\title{
Implications of the tumor immune microenvironment for staging and therapeutics
}

\author{
Janis M Taube ${ }^{1,2,3}$, Jérôme Galon ${ }^{4,5,6}$, Lynette M Sholl7 , Scott J Rodig7 ${ }^{7}$ Tricia R Cottrell ${ }^{2}$,
} Nicolas A Giraldo ${ }^{1,2}$, Alexander S Baras ${ }^{2}$, Sanjay S Patel ${ }^{7}$, Robert A Anders ${ }^{2}$, David L Rimm ${ }^{8}$ and Ashley Cimino-Mathews ${ }^{2,3}$

${ }^{1}$ Department of Dermatology, The Johns Hopkins University SOM and Bloomberg-Kimmel Institute for Immunotherapy, Baltimore, MD; ${ }^{2}$ Department of Pathology, The Johns Hopkins University SOM and Bloomberg-Kimmel Institute for Immunotherapy, Baltimore, MD, USA; ${ }^{3}$ Department of Oncology, The Johns Hopkins University SOM and Bloomberg-Kimmel Institute for Immunotherapy, Baltimore, MD, USA; ${ }^{4}$ INSERM, Laboratory of Integrative Cancer Immunology, Paris, France; ${ }^{5}$ Université Paris Descartes, Sorbonne Paris Cité, Paris, France; ${ }^{6}$ Sorbonne Universités, UPMC Univ Paris 06, Centre de Recherche des Cordeliers, Paris, France; ${ }^{7}$ Department of Pathology, Brigham and Women's Hospital, Boston, MA, USA and ${ }^{8}$ Department of Pathology, Yale University School of Medicine, New Haven, CT, USA

\begin{abstract}
Characterizing the tumor immune microenvironment enables the identification of new prognostic and predictive biomarkers, the development of novel therapeutic targets and strategies, and the possibility to guide first-line treatment algorithms. Although the driving elements within the tumor microenvironment of individual primary organ sites differ, many of the salient features remain the same. The presence of a robust antitumor milieu characterized by an abundance of CD8+ cytotoxic T-cells, Th1 helper cells, and associated cytokines often indicates a degree of tumor containment by the immune system and can even lead to tumor elimination. Some of these features have been combined into an 'Immunoscore', which has been shown to complement the prognostic ability of the current TNM staging for early stage colorectal carcinomas. Features of the immune microenvironment are also potential therapeutic targets, and immune checkpoint inhibitors targeting the PD-1/ PD-L1 axis are especially promising. FDA-approved indications for anti-PD-1/PD-L1 are rapidly expanding across numerous tumor types and, in certain cases, are accompanied by companion or complimentary PD-L1 immunohistochemical diagnostics. Pathologists have direct visual access to tumor tissue and in-depth knowledge of the histological variations between and within tumor types and thus are poised to drive forward our understanding of the tumor microenvironment. This review summarizes the key components of the tumor microenvironment, presents an overview of and the challenges with PD-L1 antibodies and assays, and addresses newer candidate biomarkers, such as CD8+ cell density and mutational load. Characteristics of the local immune contexture and current pathology-related practices for specific tumor types are also addressed. In the future, characterization of the host antitumor immune response using multiplexed and multimodality biomarkers may help predict which patients will respond to immune-based therapies.
\end{abstract}

Modern Pathology (2018) 31, 214-234; doi:10.1038/modpathol.2017.156; published online 1 December 2017

The evolution of cancer is influenced by intricate interactions between tumor cells and the host immune response within the tumor microenvironment. Surgical pathologists are uniquely positioned

Correspondence: Dr A Cimino-Mathews, MD, Departments of Pathology and Oncology, The Johns Hopkins University SOM and Bloomberg-Kimmel Institute for Immunotherapy, Weinberg Building, Room 2242, 401N. Broadway Street, Baltimore, MD 21287, USA.

E-mail: acimino@jhmi.edu

Received 23 June 2017; revised 6 September 2017; accepted 24 September 2017; published online 1 December 2017 to evaluate the prognostic and predictive features of a cancer's immune microenvironment. Several immune populations actively participate in tumorimmune regulation; however, our AJCC/UICC-TNM staging system follows a 'tumor autonomous' paradigm, whereby only features intrinsic to the tumor (depth of invasion, number of lymph nodes involved by metastases, etc.) are assessed as prognostic features. Indeed, cellular elements of both the innate and adaptive immune response impact tumor progression. ${ }^{1,2}$ Cytotoxic T cells, B cells, and macrophages can orchestrate tumor cell elimination, while other populations such as regulatory $\mathrm{T}$ cells (Tregs) 
and myeloid-derived suppressor cells can dampen the antitumor immune response and promote malignant cell growth and tissue invasion ${ }^{3}$ (Figure 1). Galon and colleagues demonstrated that the type, density, and location of immune cells within tumor samples is a superior prognostic biomarker in colorectal carcinoma when compared with current TNM staging. A potential clinical translation of the immune contexture into a prognostic marker has been established, designated the 'Immunoscore'., ${ }^{4}$ The Immunoscore is currently being investigated in a broad range of tumor types as a supplement to the current TNM staging system.

\section{Immune checkpoints}

The initiation of the adaptive immune response requires two signals, the first via antigen presentation between the major histocompatibility complex (MHC) and the T-cell receptor (Signal 1), and the second via CD28 costimulation with B7 (CD80 or CD86) (Signal 2). Once an immune response is initiated, the duration and amplitude of the response is modulated by a number of different checkpoints. One of these is CTLA-4, which has a much stronger affinity for the B7 molecules than CD28. CTLA-4 is upregulated approximately $48 \mathrm{~h}$ after T-cell activation and leads to attenuation of the immune response at the priming phase by checking early activation of naive and memory $\mathrm{T}$ cells via dominant-negative signaling. Another major checkpoint is the programmed death 1 (PD-1)/programmed death ligand1 (PD-L1) pathway, which functions in the peripheral tissues in the effector phase of the immune response. Its role is thought to be to turn off the immune response and avoid potential autoimmunetype damage following long-term antigen exposure, such as during chronic viral infections. ${ }^{6}$

The PD-1/PD-L1 checkpoint is of particular interest because tumors can co-opt this pathway to dampen the local host immune response to tumor. PD-L1-mediated adaptive immune resistance was first described in melanoma. ${ }^{7}$ In this mechanism, surveilling T-cells recognize tumor neoantigens as foreign and become activated, upregulating PD-1 and secreting interferon-gamma (IFN- $\gamma$ ) (Figure 2a). In response to IFN- $\gamma$, the tumor cells and immune cells in the immediate tumor microenvironment express PD-L1. The PD-L1 then ligates PD-1, turning off the surveilling T-cells. PD-L1-mediated adaptive immune resistance by tumors has now been extended to a large number of tumor types, including non-small-cell lung carcinoma, Merkel cell carcinoma, anal squamous cell carcinoma, breast carcinoma, and hepatocellular carcinoma, among others. ${ }^{8-13}$ Oncogenic alterations have also been implicated in modulating PD-L1 expression, including PTEN loss, ${ }^{14,15}$ selective 9p24.1 gene amplification, ${ }^{16}$ and activation of the AKT-mTOR ${ }^{17}$ or JAK/STAT pathways. ${ }^{18,19}$ Some oncogenic events

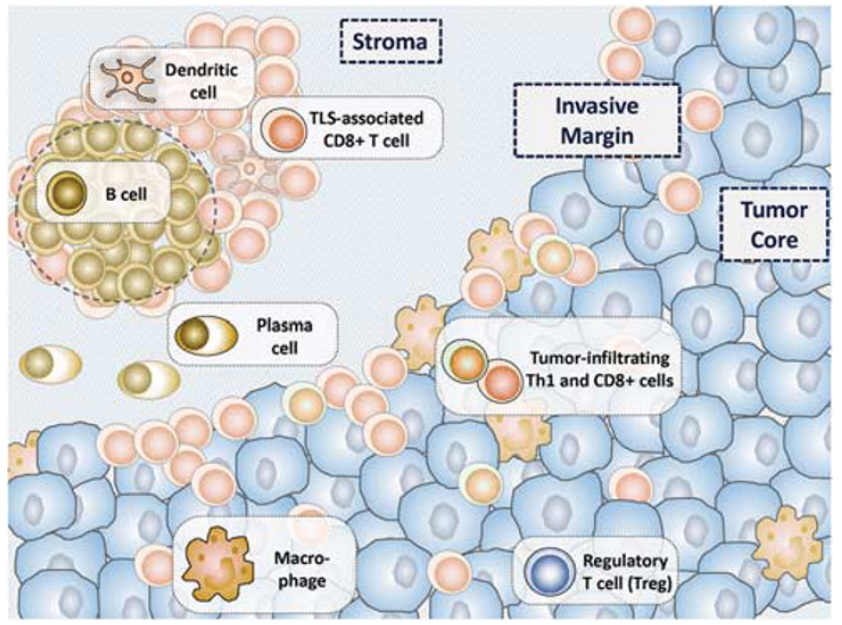

Figure 1 The immune contexture of a tumor dynamically shapes the tumor microenvironment in both a pro-tumorigenic and antitumorigenic manner. The antitumor immune milieu is characterized by an abundance of CD8+ cytotoxic $\mathrm{T}$ cells and type 1 helper (Th1) T cells. Tertiary lymphoid structures (TLS), when present, support a local antitumor immune attack. Emerging evidence also suggests that plasma cells have a role in tumor containment and potential elimination by the immune system. The pro-tumorigenic immune milieu is characterized by regulatory $\mathrm{T}$ cells (Tregs), type 2 helper (Th2, not shown) $\mathrm{T}$ cells, and specific macrophage subsets. Tumor cells may also demonstrate immune-evasion strategies, for example, the display of immune checkpoint molecules. For many tumor types, the interaction of the tumor with the host immune system occurs at the invasive margin of the tumor or surrounding intratumoral blood vessels. The balance between the pro-tumorigenic and antitumorigenic factors affects tumor development and ultimately patient survival.

may even lead to constitutive or 'innate' PD-L1 expression on the surface of tumor cells in the absence of an activated T-cell infiltrate ${ }^{20}$ (Figure 2b). A combined (constitutive plus adaptive) pattern of PD-L1 expression may also be seen in some tumors. ${ }^{12,21}$

\section{Immune checkpoint inhibitors}

Checkpoint inhibitor immunotherapies work by blocking the immune inhibitors CTLA-4 or PD-1/ PD-L1, allowing the natural host antitumor immune response to eliminate a tumor and improve patient survival even in advanced cancers. Thus, unlike chemotherapy, radiotherapy and oncogene-targeted therapies, these agents work indirectly, ie, they are not necessarily directly antitumorigenic but work by 'releasing the brakes' to promote the host antitumor immune response. ${ }^{22,23}$ The kinetics of the responses are related to this distinct 'indirect' mechanism of action. Most responses occur between 2 and 12 weeks but are relatively delayed compared with the rapid changes seen with targeted therapies, eg, rapid reduction in tumor burden with targeted BRAF inhibitor therapy in patients with melanoma. Truly delayed responses have also been reported, with patients demonstrating the first indications of a response almost a year after starting therapy. ${ }^{24}$ 
Adaptive expression
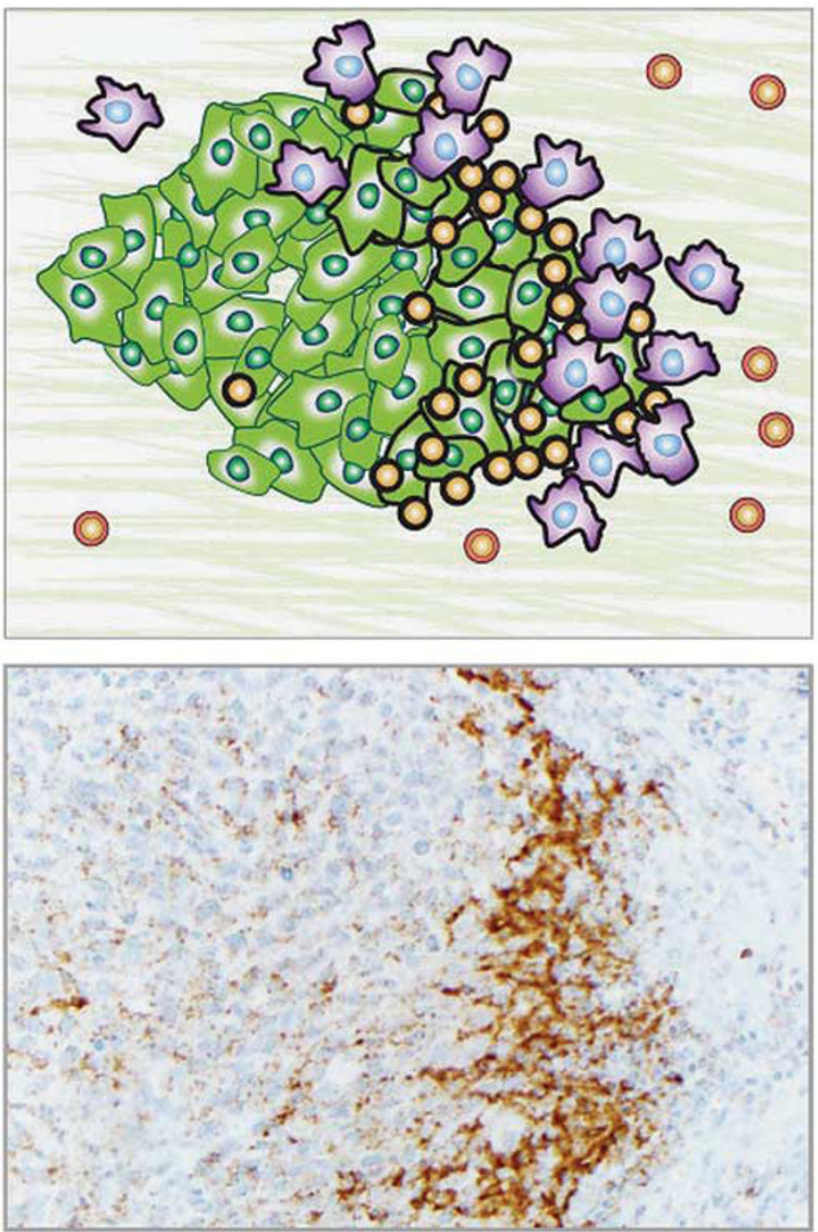

Constitutive expression
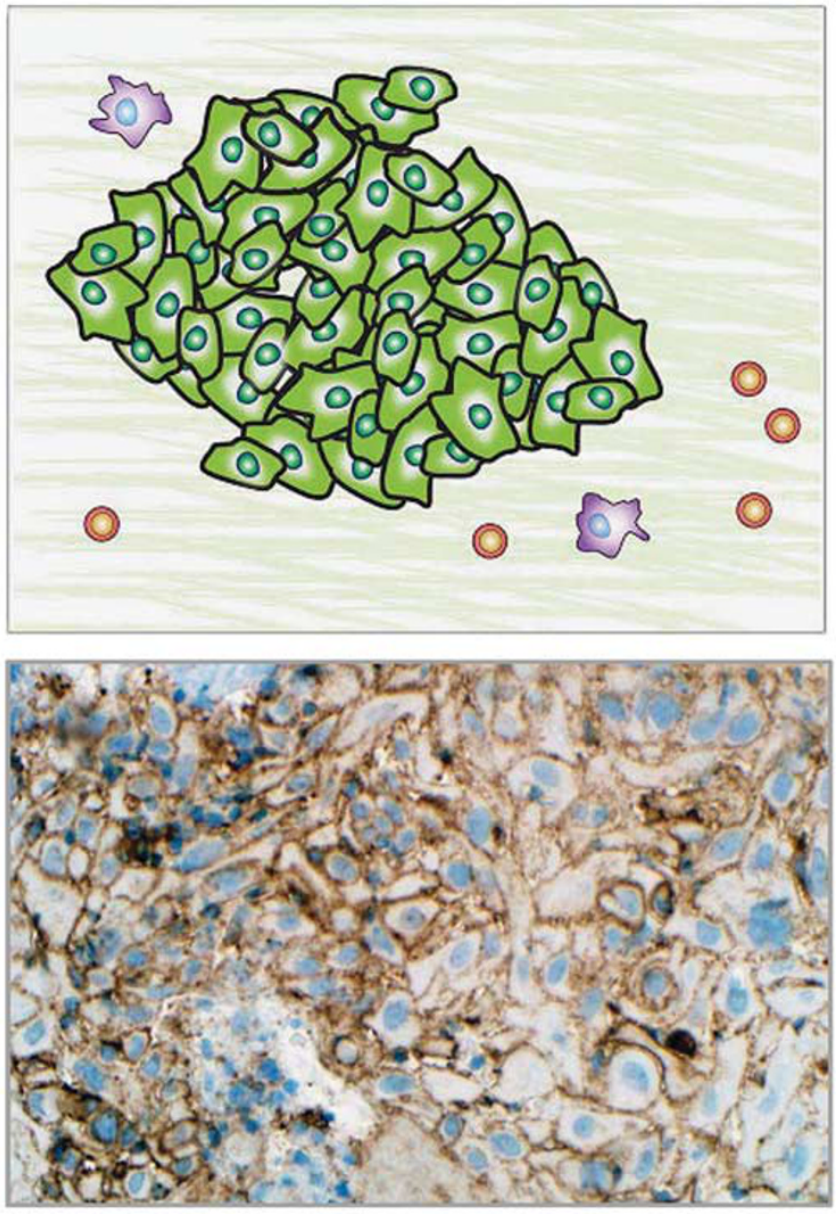

Figure 2 PD-L1 expression in the tumor microenvironment may demonstrate adaptive or constitutive expression patterns. Left panels: In adaptive PD-L1 expression, tumor and/or immune cell PD-L1 expression is geographically associated with tumor-infiltrating lymphocytes. This finding is consistent with cytokine (primarily IFN- $\gamma$ ) mediated adaptive immune resistance. Upper left panel: Schematic of PD-L1-mediated adaptive immune resistance. Tumor cells are shown in green, macrophages are purple, and TIL are orange. PD-L1 expression on the surface of the cells is denoted by a thick black line. Lower left panel: Photomicrograph shows a subcutaneous deposit of metastatic melanoma stained with immunohistochemistry for PD-L1 expression. PD-L1 expression is evident on tumor cells as well as immune cells at the host-tumor interface ( $\times 200$, original magnification). Upper right panel: Schematic showing constitutive (non-immune cell associated/diffuse) PD-L1 expression on the surface of tumor cells. Such a pattern of PD-L1 expression is likely driven by tumor intrinsic factors, such as oncogenic pathways or PD-L1 gene amplification. Lower right panel: Photomicrograph of primary head and neck squamous cell carcinoma stained with immunohistochemistry for PD-L1 expression ( $\times 250$, original magnification). PD-L1 expression is displayed on nearly every tumor cell and is independent of an immune infiltrate. Combined patterns of adaptive and constitutive expression may also be observed (not shown).

Perhaps most importantly, patients who demonstrate a response to therapy often show durable responses, even after treatment is halted; for example, a subset of patients with metastatic melanoma who responded to anti-CTLA- 4 are still alive $>10$ years later. ${ }^{25}$ This is in contrast to BRAF inhibitors in melanoma, where the median progression free survival is approximately $5-8$ months. ${ }^{26,27}$ Also distinct to this class of agents, patients can be successfully reinduced with the same drug following relapse. ${ }^{28}$ Another unusual response pattern with immunotherapy includes the radiographic picture of 'pseudo-progression', where tumors demonstrate apparent growth by scans before showing a reduction in size. This phenomenon is often attributed to effector immune cell infiltration into the tumor. ${ }^{29}$
Many of the clinical successes with these agents have been pioneered in patients with melanoma. Responses to these agents have been reported to be $\sim 20 \%$ for melanoma patients treated with antiCTLA $-4^{25}$ and nearly double that for those treated with anti-PD-1. ${ }^{30}$ As these two agents target distinct, non-redundant checkpoints, it was hypothesized that dual anti-PD-1 and anti-CTLA-4 blockade would have even greater antitumor activity. Indeed, response rates of $\sim 60 \%$ have now been reported in melanoma patients receiving combination therapy, albeit with a large proportion of patients experiencing severe immune-related side effects. ${ }^{31,32}$ United States Federal Drug Administration (FDA) approvals have been secured for all three of these regimens for patients with melanoma (Figure 3). The FDA has also 


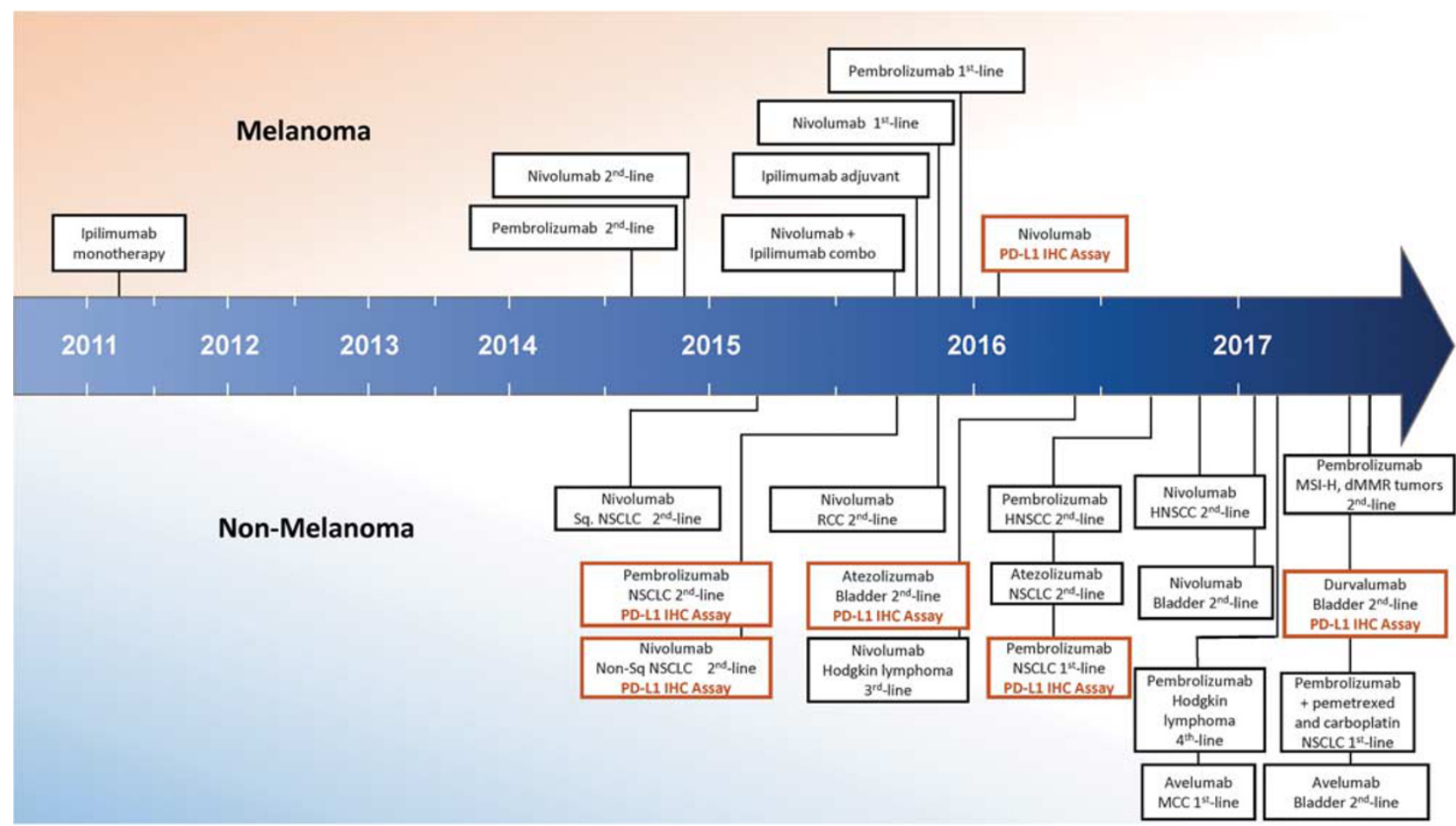

Figure 3 Timeline of FDA approvals for immune checkpoint blocking agents, including PD-L1 immunohistochemistry companion and complementary diagnostics. The earliest approvals were provided for patients with melanoma, including in 2011 for ipilimumab (antiCTLA-4), in 2014 for nivolumab and pembrolizumab (anti-PD-1 agents) monotherapy, and in 2015 for combined ipilimumab and nivolumab. Anti-PD-1/PD-L1 agents for other tumor types first received approval in 2015, and the number of indications is rapidly expanding. Companion and complimentary PD-L1 immunohistochemistry (IHC) diagnostics were first approved in 2015 for patients with non-small cell lung carcinoma (NSCLC) in the second-line setting. In late 2016, however, pembrolizumab (anti-PD-1) and the companion PD-L1 IHC diagnostic secured approval as a first-line treatment for NSCLC. (Abbreviations: combo, combination; dMMR, mismatch repair deficient; HNSCC, head and neck squamous cell carcinoma; MCC, Merkel cell carcinoma; MSI-H, microsatellite instability-high; RCC, renal cell carcinoma; Sq, squamous).

approved anti-PD-1/PD-L1 agents for the treatment of both squamous and non-squamous non-small-cell lung carcinoma, bladder carcinoma, classical Hodgkin lymphoma, head and neck squamous cell carcinoma, and Merkel cell carcinoma, with antiPD-1 therapy in non-small-cell lung carcinoma now considered a first-line approach. Most recently, the FDA approved pembrolizumab across multiple tumor types in cases with proven mismatch repair deficiency. Objective responses with anti-PD-1/PDL1 monotherapy have also been reported in tumor types as diverse as hepatocellular carcinoma, glioblastoma, mesothelioma, gastric cancer, and gynecological tract malignancies. FDA-approved regimens now also include the combination of immunotherapy with a traditional chemotherapeutic regimen (pembrolizumab with premetrexed and carboplatinin) for the treatment of patients with previously untreated metastatic non-small-cell lung carcinoma.

\section{Biomarkers of response to immune checkpoint inhibitors}

Biomarkers predictive of response or resistance to these agents are highly sought after. The most wellstudied biomarker is PD-L1 protein expression in the tumor microenvironment. Immunohistochemical assays for PD-L1 are used as predictors of response to anti-PD-1/PD-L1 therapy and are currently the only FDA-approved companion or complimentary diagnostic for this class of agents. PD-L1 immunohistochemistry assays are only approved for specific clinical settings (Figure 3), and there are well-recognized limitations to PD-L1 as a predictive biomarker. Although PD-L1 expression clearly enriches for response to anti-PD-1/PD-L1 therapy, patients lacking PD-L1 expression may still derive clinical benefit. ${ }^{33}$ Other potential biomarkers predictive of response include CD8 cell density and mutational burden. ${ }^{34-37}$ Tumor tissue-based markers of both innate and acquired resistance to these agents have also recently been reported, ${ }^{38-40}$ potentially expanding the assayable factors that may be combined in a multiplexed, multimodality assay with improved predictive value.

The purpose of this review is to introduce the concepts behind the role of the tumor immune microenvironment with a focus on the adaptive immune response and the direct clinical importance of these concepts for surgical pathologists (for reviews on the role of innate immune cells in the tumor microenvironment, see Gajewski et $a l^{1}$ and Vesely et $a l^{2}$ ). The concepts emphasized in the review include: the fundamental characterization of the tumor 
immune microenvironment, the use of immune based therapies in different tumor types, and the development of prognostic and predictive immune-based biomarkers. The surgical pathologist will undoubtedly have a critical role in furthering our understanding of the tumor immune microenvironment and in translating research findings into clinical care. Owing to the fact that most of these candidate biomarkers are assessed on tumor tissue, pathologists will be involved in continued biomarker investigations and the associated clinical assay development, as well as ultimately in their clinical use.

\section{The Immunoscore}

The Immunoscore represents an example of how elements of the immune microenvironment can be quantified in a standardized way and incorporated into a prognostic index that provides information more robust than the standard AJCC/UICC-TNM staging system. The standardized Immunoscore was based on the quantification (cells $/ \mathrm{mm}^{2}$ ) of two lymphocyte populations (CD3 and CD8) within the central region and the invasive margin of colorectal carcinoma tumors and provides a scoring system ranging from Immunoscore 0 (I0) to Immunoscore 4 (I4) (Figure 4). ${ }^{41}$ Classification by the Immunoscore has been shown to have a prognostic significance superior to that of the classical TNM system for disease-free survival, disease-specific survival, and overall survival in patients with colorectal carcinoma. ${ }^{4}$ Several followup studies confirmed the strong prognostic value in patients with colorectal carcinoma at all stages of disease. ${ }^{42-44}$ Additional studies also showed that the Immunoscore is a stronger predictor of patient survival than microsatellite instability ${ }^{45}$ and that the Immunoscore can also be of prognostic value when applied to brain metastases. ${ }^{46}$

Based on these encouraging results, a worldwide consortium composed of International Expert Pathologists and Immunologists was formed in 2012. ${ }^{47,48}$ The main objectives were to assess the feasibility, reproducibility, significance, and robustness of Immunoscore. The consortium was initially composed of 23 centers from 17 countries and received support from the Society for Immunotherapy of Cancer. The statistical analysis plan was predefined, and all statistical analyses performed by external statisticians. The primary study end point was time to recurrence for patients classified by Immunoscore (High vs Low), and the end point was reached in the three cohorts of patients tested. Analyses were performed by Cox models stratified by enrolling center. The final results supported the significant prognostic value of the Immunoscore in 3855 patients with AJCC/UICC-TNM stage I/II/III colon cancers (presented in a plenary session at the ASCO annual meeting 2016). ${ }^{44}$ The Immunoscore is currently being investigated in a broad range of tumor types as a supplement to the current TNM staging system.

\section{Diagnostic assays}

Companion and complimentary diagnostic tests aim to separate potential responders from nonresponders for a known therapeutic, that is, the test should be able to predict which patients will respond to a given drug. In the best case scenario, such a diagnostic test has high sensitivity and high specificity for drug target that leads to high sensitivity and specificity for patient selection. For PD-1/PDL1 axis therapies, there are at least five commonly used tests, four of which are FDA approved (Table 1). It is increasingly relevant for surgical pathologists to have an understanding of the available diagnostic tests, as well as the strengths and limitations of each, as we will have a role in ordering, performing, and interpreting these tests in the future.

As of the time of this publication, only one assay is a true companion diagnostic test (ie, required for the prescription of drug, in this case pembrolizumab), two are complementary diagnostic tests (ie, may be useful to inform prescribing practices but not required), one is a Class 1 diagnostic test, and one is a laboratory-developed test. Each assay has its own scoring system, contributing to the lack of harmonization across assays. Further confusion is caused by the fact that different thresholds for scoring a tumor as 'positive' are used, even within a single assay. For example, PD-L1 expression in $>50 \%$ tumor cells is required to prescribe the anti-PD-1 agent pembrolizumab in the first line in lung cancer, but only $>1 \%$ tumor cell staining is required for use in the second line.

Several studies have been conducted to assess the concordance of the available PD-L1 assay systems, ${ }^{49-52}$ while other studies have focused on only the anti-PD-L1 antibody clone itself, while essentially holding the remainder of the assay system constant. For the purpose of discussions here, when the term 'assay' is used, eg, SP142 assay, it refers to the entire marketed assay system, while, when the term 'antibody' is used, it only refers to the anti-PDL1 clone used and not the remainder of the assay system (antigen retrieval, $\mathrm{pH}$ of buffer, type of amplification, etc). The Blueprint study ${ }^{49}$ is perhaps the best-known example of an assay comparison study, as it represented the collaboration of the four leading companies with PD-1/PD-L1 axis therapies and the two companies that produced the FDAcleared diagnostic assays. This study showed that the SP142 assay detected less PD-L1 expression on tumor cells compared with the other assays. A second study that was sponsored by NCCN/BMS was multi-institutional and statistically powered and included 13 pathologists from 7 institutions. ${ }^{51}$ This study revealed that the assay using SP142 was an outlier not only for tumor cell but also immune cell assessment, in both cases selecting only about half of the cases as PD-L1-positive compared with the other three assays. Pathologists were highly concordant in scoring the tumor cell PD-L1 labeling, but 

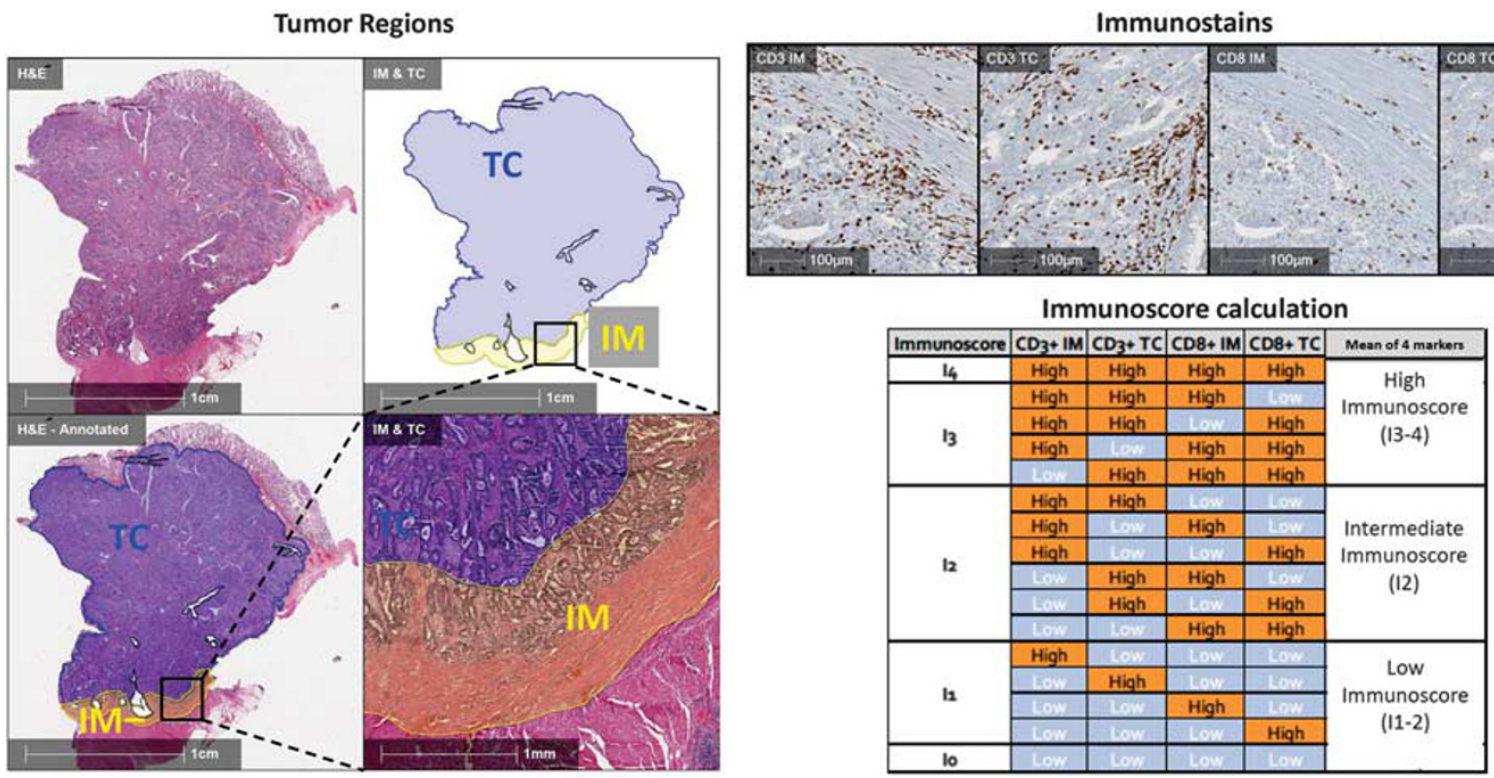

Figure 4 The Immunoscore is a standardized approach to characterizing T-cell infiltration of surgical pathology tumor specimen. Left panels: The border between the advancing tumor edge and normal tissue is annotated on a colorectal carcinoma specimen. A 500- $\mu \mathrm{m}$ distance on either side of this border is designated the 'invasive margin' (IM, yellow region). The remainder of the tumor is designated as the 'tumor core' (TC, blue region). Upper right panels: Immunohistochemistry for CD3 and CD8 is used to quantify cell densities for each of these immune cell subsets in both the invasive margin and tumor core. Lower right panels: The density of each region is labeled 'high' or 'low' density for each marker. The mean percentile of the four immune parameters is calculated, resulting in a possible Immunoscore ranging from I0 to I4, or three categories (Low, Intermediate, High). (Abbreviations: IM, invasive margin; TC, tumor core).

Table 1 Comparison of PD-L1 immunohistochemical assays

\begin{tabular}{|c|c|c|c|c|c|}
\hline Assay & $22 C 3$ & $28-8$ & $S P 142$ & SP263 & E1L3N \\
\hline Platform & Dako Link 48 & Dako Link 48 & Ventana Benchmark & $\begin{array}{l}\text { Ventana } \\
\text { Benchmark }\end{array}$ & LDT_Leica Bond \\
\hline Drug & Pembrolizumab & Nivolumab & Atezolizumab & Durvalumab & None/any \\
\hline Vendor & Merck & BMS & Genentech & Astra Zeneca & None/any \\
\hline Tissue scored & Tumor cells & Tumor cells & $\begin{array}{l}\text { Tumor cell and/or immune } \\
\text { cells }\end{array}$ & $\begin{array}{l}\text { Tumor cell and/ } \\
\text { or immune cells }\end{array}$ & $\begin{array}{l}\text { Tumor cell and/ } \\
\text { or immune cells }\end{array}$ \\
\hline Scoring system & $\begin{array}{l}>50 \% \\
>1 \% \\
0 \%\end{array}$ & $\begin{array}{l}>10 \% \\
>5 \% \\
>1 \% \\
0 \%\end{array}$ & $\begin{array}{l}\text { Scoring system integrating TC } \\
\text { and IC scores, eg, } \\
\text { TC3 }=>50 \% ; \text { IC3 }=>10 \% \\
\text { TC0 and } \text { IC0 }=0 \% \text {, etc. }\end{array}$ & $\begin{array}{l}>25 \% \\
1-25 \% \\
0 \%\end{array}$ & $\begin{array}{l}\text { No assay-specific } \\
\text { scoring system }\end{array}$ \\
\hline FDA status & $\begin{array}{l}\text { Companion Dx in } \\
\text { NSCLC }\end{array}$ & $\begin{array}{l}\text { Complementary Dx } \\
\text { in NSCLC }\end{array}$ & $\begin{array}{l}\text { Complementary Dx in NSCLC } \\
\text { and Bladder }\end{array}$ & Class 1 Dx & None (LDT) \\
\hline $\begin{array}{l}\text { Ratcliffe, et al-most } \\
\text { and least concordant } \\
\text { (concordance) }^{\mathrm{a}}\end{array}$ & $\begin{array}{l}\text { Most: } 28-8(93.7 \%) \\
\text { Least: SP263 } \\
(91.1 \%)\end{array}$ & $\begin{array}{l}\text { Most: 22c3 }(93.7 \%) \\
\text { Least: SP263 } \\
(91.7 \%)\end{array}$ & Not tested & $\begin{array}{l}\text { Most: 22c3 } \\
\text { (91.7\%) Least: } \\
28-8(91.1 \%)\end{array}$ & Not tested \\
\hline $\begin{array}{l}\text { Blueprint Study- } \\
\text { most and least } \\
\text { concordant }^{\mathrm{b}} \\
\text { (concordance) }\end{array}$ & $\begin{array}{l}\text { Most: } 28-8(94.7 \%) \\
\text { Least: SP142 } \\
(86.8 \%)\end{array}$ & $\begin{array}{l}\text { Most: 22c3 (94.7\%) } \\
\text { Least: SP142 } \\
(81.6 \%)\end{array}$ & $\begin{array}{l}\text { Most: SP263 }(65.8 \%) \\
\text { Least: 22c3 or } 28.8(63.2 \%)\end{array}$ & $\begin{array}{l}\text { Most: } 22 \mathrm{c} 3 \text { or } \\
28.8(89.5 \%) \\
\text { Least: } \mathrm{SP} 142 \\
(86.8 \%)\end{array}$ & Not tested \\
\hline $\begin{array}{l}\text { NCCN/BMS- } \% \text { cases } \\
\text { at }>50 \% \text { and }>1 \% \\
\text { cut points }^{\mathrm{C}}\end{array}$ & $\begin{array}{l}>50 \%=19 \% \\
>1 \%=64 \%\end{array}$ & $\begin{array}{l}>50 \%=23 \% \\
>1 \%=79 \%\end{array}$ & $\begin{array}{l}>50 \%=6 \% \\
>1 \%=32 \%\end{array}$ & Not tested & $\begin{array}{l}>50 \%=24 \% \\
>1 \%=72 \%\end{array}$ \\
\hline
\end{tabular}

Abbreviations: Dx, diagnostic; LDT, laboratory-developed test.

${ }^{a}$ Overall percentage agreement at $>1 \%$ cut point, taken from Table 1 of Ratcliffe et al. ${ }^{50}$

${ }^{\mathrm{b}}$ Concordance between assays at positive-negative cut point for each test, taken from Table 2 in Hirsch et al. ${ }^{49}$

${ }^{\mathrm{C}}$ Percentage of positive cases for tumor cells at two cut points, taken from Figure 2 of Rimm et al. ${ }^{51}$

they were unable to achieve concordance in scoring the immune cell PD-L1 labeling. The NCCN/BMS study did not include the SP263 assay but rather substituted a laboratory-developed test.
This laboratory-developed test performed statistically equivalent to the Dako 28-8 assay, indicating that a laboratory-developed test has the potential to match the characteristics of the FDA-approved test. 
Also germane to laboratory-developed test use, two different studies in non-small-cell lung carcinoma and melanoma showed that many of the anti-PD-L1 antibodies themselves (including the SP142 antibody) have the potential to demonstrate similar analytic performance and that it is the assay conditions that drive the resultant differences. ${ }^{53,54}$

To date, none of the studies comparing PD-L1 antibodies and assays have been performed on tissue from patients treated with PD-1 axis therapies. As a result, these studies have not been able to assess predictive value of the assays across therapies. Questions thus remain regarding which tests are required, which should be used, and whether they are all the same or if each has its own biological meaning. These questions are likely to be resolved in the near future. However, other issues inherent to stratifying patients as PD-L1-positive vs -negative by immunohistochemistry will remain. Perhaps the biggest issue is that, in nearly every cohort tested, there are patients with clinical benefit in the subgroup with no PD-L1 expression. ${ }^{33}$ Although no test is perfectly sensitive, the sensitivity of the current immunohistochemical PD-L1 assays is lower than optimal. Recent efforts to increase sensitivity by including patients with lower cut points have failed, ${ }^{55}$ whereas studies with higher specificity (potentially at the expense of sensitivity) resulted in superior performance of pembrolizumab when compared with chemotherapy in the first line in lung cancer. ${ }^{56}$

There are a number of other issues that affect the results of PD-L1 assays that lack published scientific support. One key issue is the number of cells required for an adequate assay. The FDA label for the PD-L1 immunohistochemistry assay using antibody clone $22 \mathrm{C} 3$ requires that the specimen contain at least 100 tumor cells; however, there is no published scientific data supporting this cut point. A number of recent abstracts have suggested that cytology specimens may be adequate for PD-L1 assessment, but to date, none are published or associated with drug response data. Specimen cell number and specimen type are both dependent on inherent heterogeneity of the expression of PD-L1. PD-L1 expression within a tumor can be heterogeneous ${ }^{57}$ where different regions of the same section show different levels of expression. This has led to concerns that small biopsies may miss the region of the tumor with high PD-L1 expression. Rehman et $a 1^{58}$ further evaluated PD-L1 heterogeneity and noted that PD-L1 variation was greater within a single tumor slide than between tumor blocks, suggesting that core biopsies may be sufficient to sample heterogeneity across a tumor. However, while this assessment begins to define the heterogeneity of PD-L1 expression, this work does not define the minimum number of fields of view of PD-L1 required for a representative biopsy, as this data set was not supported by treatment outcome information.
Alternative predictive tests have focused on genomic tests, RNA signatures, or multiplexed fluorescence-based assessment of the tumor microenvironment. Whole-exome sequencing revealed that patients with high mutational load showed an increased likelihood of response to immune checkpoint inhibitors ${ }^{36}$ based on the concept that more mutations resulted in more neoantigens, which increased the likelihood of checkpoint-mediated immune inhibition. However, this predictive method has been limited by the fact that some patients with low mutational load also respond to PD-1 axis therapies. $P D-L 1 / P D-L 2$ amplification at chromosome 9p24.1 is a genetic basis for PD-L1 overexpression in a subset of lymphomas and solid tumors. This amplification has been shown to be predictive of improved clinical response among patients with classical Hodgkin lymphoma treated with PD-1 blockade and can identify novel tumor types with exquisite sensitivity to PD-1 blockade. ${ }^{59,60}$ However, the prognostic and predictive power has yet to be determined for additional tumor types that can harbor this genetic lesion. ${ }^{61,62}$ RNA signatures have also been designed to assess the immunological profile of the patients' immune response to the tumor. Early studies on the Nanostring platform suggest that an 18 gene panel can enrich for response to pembrolizumab with comparable sensitivity and specificity as PD-L1 immunohistochemical testing. ${ }^{63}$ Finally, a number of groups have attempted to quantitatively assess the immune cell microenvironment using multiplex immunofluorescence. ${ }^{64,65}$ The studies have focused on T-cells combined with other markers (Figure 5), but it is too early to assess sensitivity and specificity of this approach.

\section{Melanoma and other cutaneous malignancies}

Studies on patients with advanced melanoma largely pioneered the use of checkpoint agents and associated biomarker discoveries. Ipilimumab (antiCTLA-4) was the first checkpoint agent approved by the FDA for the treatment of advanced melanoma, based on an objective response rate of $11 \%$ as well as prolonged survival in $22 \% .^{25,66}$ Nivolumab and pembrolizumab (anti-PD-1) were the next agents to garner FDA approval, with patients with advanced melanoma showing increased objective response rates on the order of $30-40 \% .^{30,67,68}$ Most recently, dual anti-CTLA-4/PD-1 blockade has received FDA approval based on response rates as high as $55 \%$, albeit with a notable side effect profile. ${ }^{69}$ Each of these regimens is now considered standard of care for patients with advanced melanoma.

As with many other tumor types, PD-L1 expression is recognized as a biomarker for response to PD-1/ PD-L1 checkpoint blockade. In fact, the adaptive resistance pattern of PD-L1 expression was first 

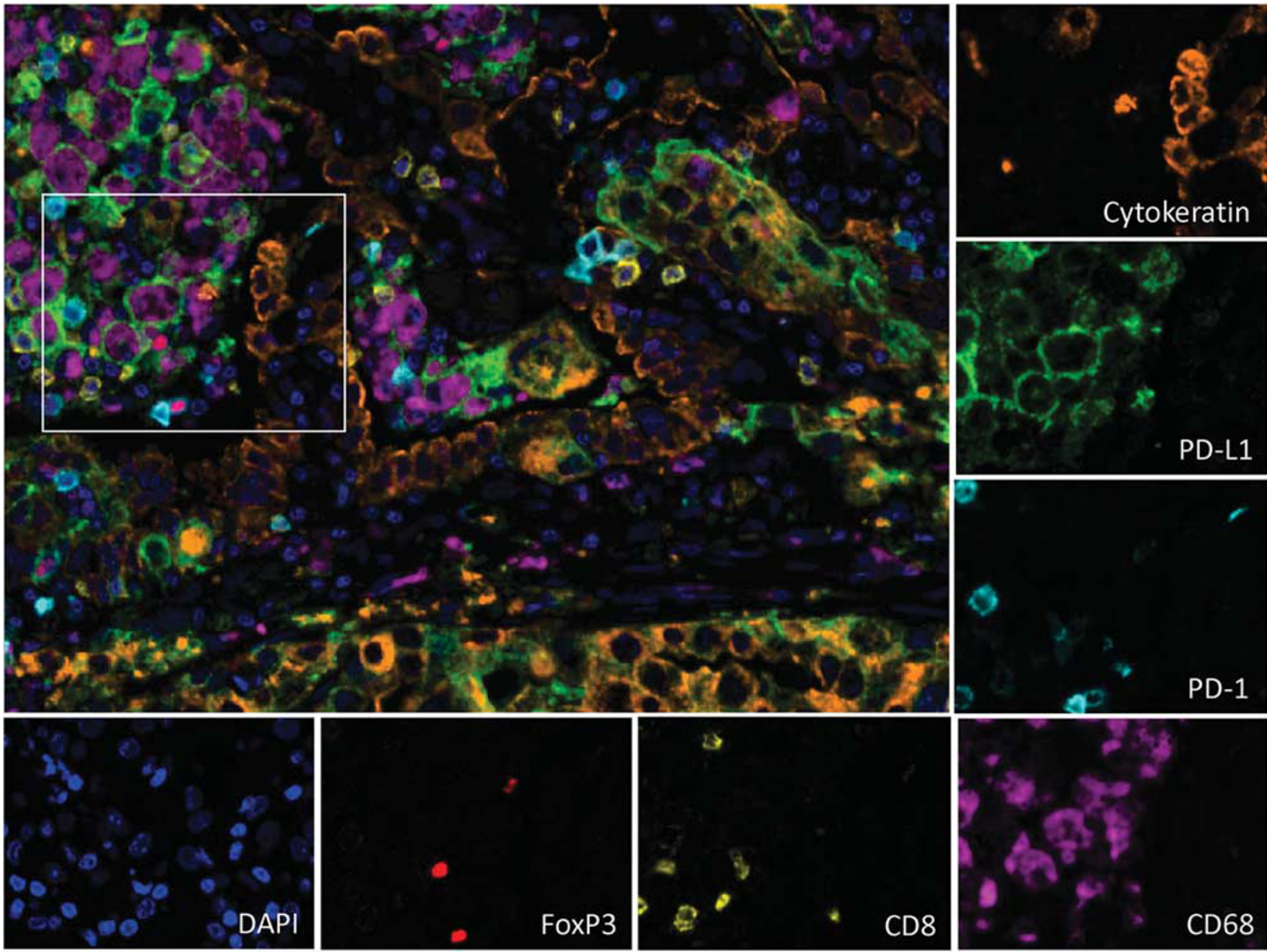

Figure 5 Multiplex immunofluorescence staining of a pulmonary non-small cell carcinoma (adenocarcinoma) in a formalin-fixed, paraffin-embedded section. Tumor cells (orange) and CD68+ macrophages (purple) both express PD-L1 (green). Rare CD8+ T-cells (yellow) are also present, some of which express PD-1 (cyan). Singular FoxP3+ regulatory T-cells (red) are also identified. The nuclei for each cell is stained with DAPI (blue) ( $\times 200$, original magnification). The tumor in this example is expressing PD-L1 in a constitutive pattern, that is, independent of the degree of immune infiltrate.

described in melanoma. ${ }^{7}$ It is by far the dominant mechanism of PD-L1 display in this tumor type, with constitutive expression reported in only $\sim 1 \%$ of cases. The adaptive pattern of PD-L1 expression also predominates in melanoma subtypes, such as ocular, desmoplastic, acral, and mucosal melanomas. ${ }^{70}$ Adaptive PD-L1 expression is a positive prognostic feature when expressed by either tumor cells or tumor-associated immune cells. ${ }^{7}$ Both melanocyte and immune cell PD-L1 display is primarily IFN- $\gamma$ driven, though other cytokines such as interleukin10 may preferentially contribute to macrophage as opposed to tumor cell PD-L1 expression. ${ }^{71}$ Importantly, PD-L1 expression is independent of the BRAF $^{V 600 E}$ mutation, indicating that these two features should be considered separate biomarkers for therapeutic selection in patients with advanced disease. ${ }^{72}$

PD-L1 expression is closely related to PD-L2 expression, the second ligand for PD-1. In fact, when whole transcriptome associations are performed, PDL2 is the gene most closely associated with PD-L1 expression in melanoma. ${ }^{73}$ Not surprisingly, PD-L2 expression is also a positive prognostic feature in these patients, ${ }^{73,74}$ likely because, similar to PD-L1, its expression in this tumor type tends to equate with an ongoing host response against tumor. The impact of PD-L2 expression as a predictive biomarker for anti-PD-1 blockade is not well understood at this time but is currently being explored by a number of investigative groups. Additional features of the PD-1/ PD-L1 interaction in pretreatment specimens, such as CD8 density, ${ }^{34}$ levels of PD-L1 expression, ${ }^{75}$ and PD-1-PD-L1 interaction, ${ }^{76}$ may have added value beyond the determination of whether PD-L1 is simply present or absent.

Other potential tissue-based biomarkers of response and resistance to checkpoint blockade in patients with melanoma include specific gene expression profiles and genomic features. Transcriptional signatures have been identified involving genes associated with wound healing and remodeling of the extracellular matrix, mesenchymal transition, and angiogenesis. ${ }^{38}$ When expressed 
simultaneously, these gene signatures have been proposed to confer an innate resistance to PD-1 therapy. Specific genetic resistance mechanisms to anti-PD-1 have also been identified in patients with melanoma, including $J A K 1 / 2$ mutations, influencing the response to IFN- $\gamma$, and B2 microglobulin loss, leading to a lack of MHC class I expression. ${ }^{39,40}$ Most recently, an increase in copy number alteration has been associated with decreased immune infiltration and a more resistant phenotype to sequential antiCTLA-4, anti-PD-1 blockade. ${ }^{77}$

Patients with other advanced cutaneous malignancies, including Merkel cell carcinoma, squamous cell carcinoma, and basal cell carcinoma, have also been treated with checkpoint inhibitors. Patients with Merkel cell carcinoma have shown response rates of 56 and $32 \%$ to anti-PD-1 and anti-PD-L1, respectively, the latter of which is now FDA approved. ${ }^{64,78}$ When biomarkers of response to anti-PD-1 were studied in patients with Merkel cell carcinoma, neither PD-L1 expression, mutational load, or viral status were predictive ${ }^{64}$; however, preliminary results suggest that the density of PD-1+ cells within $15 \mu \mathrm{m}$ of a PD-L1+ cell may be associated with response to therapy. ${ }^{79}$ Early reports suggest that patients with aggressive squamous cell and basal cell carcinomas may also respond to immune checkpoint blockade therapy. ${ }^{80-82}$

\section{Non-small-cell lung carcinoma}

Lung cancer represents one of the greatest sources of cancer-related morbidity and mortality worldwide. ${ }^{83}$ Incremental gains in lung cancer survival have been driven by the use of combined platinum and pemetrexed chemotherapies, ${ }^{84}$ as well as identification and directed therapy of oncogenic alterations in EGFR, $A L K$, and $R O S 1^{85,86}$ using tyrosine kinase inhibitors. However, the benefits to survival attributable to the evolution of chemotherapy strategies are small, and targeted therapies are applicable to only a minor subset of patients with lung cancer. For instance, fewer than one-third of lung adenocarcinoma patients in Western countries will qualify for EGFR or ALK/ROS1 inhibitors. Therefore, clinical trials showing that immunotherapies confer a survival benefit over chemotherapy for patients with lung cancer have been greeted with great enthusiasm. As of May 2017, three immune checkpoint blockade inhibitors have been approved by the FDA for use in non-small-cell lung carcinoma, the anti-PD-1 antibodies pembrolizumab (first- and second-line setting) and nivolumab (second line) and the anti-PD-L1 antibody atezolizumab (second line).

Response rates vary based on drug, line of therapy, and histological subtype (squamous vs nonsquamous non-small-cell lung cancer). Immunohistochemical staining for PD-L1 on tumor and immune cells has emerged as the dominant biomarker for selection of lung cancer patients for anti-PD-1 and
PD-L1 antibody therapy, with the previously discussed limitations. As noted above, only the PD-1 inhibitor pembrolizumab requires a priori knowledge of the PD-L1 protein expression status in clinical practice based on clinical trials (KEYNOTE) showing superior outcomes relative to chemotherapy. However, different PD-L1 expression cutoffs are used for pembrolizumab eligibility in the first- and second-line setting. Correlative biomarker analyses in the phase 1, KEYNOTE-001 trial (which included both untreated and previously treated patients) demonstrated that patients with PD-L1 labeling in at least $50 \%$ of tumor cells had a higher likelihood of response to pembrolizumab and longer progressionfree and overall survival than those whose tumors had lower levels of PD-L1 expression. ${ }^{87}$ The authors recognized, however, that some patients with lower levels of tumor PD-L1 expression also benefitted from immune checkpoint blockade. Indeed, subsequent phase 2 and 3 trials found that PD-L1 labeling in $1 \%$ of tumor cells also predicted improved survival with second-line pembrolizumab compared with standard-of-care chemotherapy in previously treated patients. ${ }^{88}$ In the first-line setting, a phase 3 trial of pembrolizumab monotherapy showed striking improvements in progression-free and overall survival relative to platinum-based chemotherapy but was restricted to patients with at least $50 \%$ tumor cell staining with PD-L1. ${ }^{56}$

Another PD-1 inhibitor, nivolumab, has also been approved for use in the second line; however, firstline trials (CHECKMATE-026) failed to show a benefit over chemotherapy when patients were stratified based on PD-L1 status. ${ }^{55,89}$ In addition to potential differences in the anti-PD-1 agents' activity, some other possible explanations for the disparate trial results include the different biomarker selection criteria, differing time intervals between specimen acquisition and treatment initiation, and statistical power of the studies to examine the correlation between different PD-L1 thresholds and response, as well as a history of possible prior radiation therapy. ${ }^{55,90}$ It is also important to note that patients with EGFR mutations and $A L K$ rearrangements do not appear to benefit from immune checkpoint blockade and were excluded from trials in the firstline setting. As a result, patients with a new diagnosis of advanced-stage lung adenocarcinoma should undergo testing for EGFR mutations, $A L K$ and ROS1 rearrangements, and PD-L1 protein expression to determine eligibility for tyrosine kinase inhibitors and pembrolizumab therapy, respectively.

In addition to PD-L1 expression, the factors that may predict response to checkpoint blockade inhibitors in lung cancers include underlying oncogenic pathway activation, tumor mutation and/or neoantigen burden, and the tumor immune microenvironment. There is little doubt that a combination of these factors contributes to PD-1/PD-L1 axis engagement and influences the nature of the tumor cellimmune cell interaction. As with hypermutated, 
microsatellite-high tumors of the colon, endometrium, and other sites, highly mutated lung cancers with smoking-related, transversion-high signatures appear significantly more likely to overexpress PDL1 and to respond to PD-1 inhibition. ${ }^{36,91}$ Mechanistically, smoking-related transversion mutations in non-small-cell lung carcinoma contribute to neoantigen formation with resulting T-cell recruitment. IFN$\gamma$ release from tumor-infiltrating $\mathrm{T}$ cells may trigger adaptive upregulation of tumor PD-L1 and engagement with PD-1 expressing $\mathrm{T}$ cells, preventing immune attack. PD-1 inhibitors may be effective in unleashing the immune system in this scenario; however, a number of other tumor-specific factors are likely to influence the efficacy of this therapeutic strategy. Of note, reanalysis of the CHECKMATE-026 trial found that high tumor mutation burden, defined as >243 mutations by whole-exome sequencing, correlated with improved progression free survival and objective response rate in non-small-cell lung carcinoma patients receiving first-line nivolumab as compared with chemotherapy. Although tumor mutation burden or the combination of tumor mutation burden and high PD-L1 expression appeared to outperform PD-L1 alone as predictive biomarkers, the study was not powered for formal statistical analysis of these variables outperforming PD-L1 as a predictive biomarker in this setting. ${ }^{89}$

Studies correlating oncogenic-driver mutations with the quality and quantity of immune infiltrates as well as the efficacy of PD-1/PD-L1 blockade have not been definitive. Some studies have failed to identify a correlation between tumor genotype and immunoprofile, ${ }^{92}$ while others have suggested that KRAS/TP53 mutation status predicts for tumor adaptive immune resistance that may be amenable to PD-1 pathway blockade. ${ }^{91}$ STK11 loss-of-function mutations, which occur in $10-15 \%$ of lung adenocarcinomas, tend to co-occur with KRAS mutations, appear to promote recruitment of neutrophils to the tumor and exclude T-cell infiltrates, ${ }^{93-95}$ and thus may confer relative resistance to immune checkpoint blockade. Therefore, it is likely that tumor genetics have an important role in defining the non-small-cell lung carcinoma tumor immune response.

\section{Renal cell carcinoma}

Immune infiltrates in renal cell carcinoma are prominent, and two main tumor immune microenvironment milieus have been described. In the majority of cases, the immune infiltrate is composed of poorly functional dendritic cells and anergic $\mathrm{T}$ cells. ${ }^{96-98}$ Renal cell carcinomas also rarely display peritumoral immune aggregates or tertiary lymphoid structures and therefore lack privileged sites for T-cell priming. ${ }^{99,100}$ In fact, renal cell carcinoma is one of the few cancer types where increased densities of CD8+, CD4+, and PD-1+ tumorinfiltrating $\mathrm{T}$ cells correlate with poor clinical outcomes. ${ }^{101-103}$ The second type of microenvironment is more consistent with what is typically seen in other tumor types, namely, the CD8+ infiltrate is activated and represents an ongoing antitumor response that is associated with an improved prognosis. This phenotype has been characterized by using CD8 and Ki-67 double immunohistochemistry staining or the presence of an IFN- $\gamma /$ Th1-type gene signature. ${ }^{104}$ PD-L1 and PD-L2 expression has also been reported in renal cell carcinoma. ${ }^{73,103,105,106}$ However, the relationship between the two tumor immune microenvironments and the presence and pattern (adaptive vs constitutive) of PD-L1 and PD-L2 expression has yet to be thoroughly explored.

Renal cell carcinoma has long been recognized as an immunogenic tumor and indeed was one of the first cancer types that displayed objective responses after treatment with recombinant interleukin2. ${ }^{107,108}$ Metastatic renal cell carcinoma is one of the tumor types that showed responses in early clinical trials for therapies blocking the PD-1/PD-L1 axis. ${ }^{109,110}$ Three clinical trials evaluating the efficacy of anti-PD-1 (nivolumab or atezolizumab) or anti-PD-L1 (MDX 1105) agents focused on patients with renal cell carcinoma have reported objective response rates ranging from 15 to $25 \% .{ }^{111-113}$ PD-L1 expression by both tumor cells and immune cells has been investigated as a biomarker of response and, in general, trends toward an association. However, it has not shown as clear cut of a significance as a biomarker of response or progression-free survival, perhaps because PD-L1 expression may not be predominantly IFN- $\gamma$ driven in this tumor type. ${ }^{73}$

\section{Urothelial carcinoma}

The immune contexture in muscle-invasive urothelial neoplasms correlates with postcystectomy survival. Increased CD8+ infiltrates confer a favorable prognosis, ${ }^{114}$ whereas increased Treg infiltrates are associated with a worse prognosis. ${ }^{115}$ Tumor cell PDL1 expression is observed in $\sim 20 \%$ of muscle invasive urothelial carcinomas. ${ }^{114,116}$ Increased tumor cell PD-L1 expression is generally associated with higher-stage disease, but an association with postcystectomy survival has not been consistently observed across multiple cohorts. ${ }^{114,117-122}$ Many of the observed differences between these studies may be attributable to the use of different PD-L1 immunohistochemistry protocols, antibodies, scoring criteria, and sample sizes-again highlighting the perils of trying to compare across studies when there is a lack of assay harmonization and a unified scoring approach.

Urothelial carcinoma has a long-standing history of immune-based therapeutic approaches. In particular, the treatment of non-muscle invasive urothelial carcinoma with intravesical Bacillus-CalmetteGuerin (BCG) has proven to be an effective strategy with significant reduction in progression and 
cancer-related death. ${ }^{123}$ More recently, successful PD-1/PD-L1 blockade therapy in urothelial carcinoma has led to FDA approvals for certain clinical indications. ${ }^{124,125}$ More specifically, the early studies were performed in patients with muscle invasive carcinoma; however, trials are currently underway for non-muscle-invasive disease (NCT02451423, NCT02625961). When tumor cell and immune cell PD-L1 expression were evaluated as potential biomarkers of response to therapy in this tumor type, investigators found that immune cell PDL1 expression is more predictive of response to PD1/ PD-L1 signaling inhibition than tumor cell PD-L1 expression. ${ }^{125}$ This may be because there is a component of constitutive PD-L1 expression by tumor cells, as has been reported in tumors arising from squamous-type epithelium ${ }^{12,126}$ (Figure 2b). Notably, the immune contexture is also predictive of response to non-immune-based therapies such as conventional platinum-based neoadjuvant chemotherapy, whereby an increasing ratio of Treg to CD8 density is predictive of residual muscleinvasive tumor posttreatment. ${ }^{116}$

\section{Hodgkin lymphoma and other hematologic malignancies}

Hematological malignancies, much like certain solid tumors, have shown some early and encouraging results with PD-1 blockade. Classical Hodgkin lymphoma has been the most well studied thus far and has seen a relatively rapid progression from biomarker identification to clinical application. Specific chromosomal gains were identified in classical Hodgkin lymphoma, including 9p, by comparative genomic hybridization analyses of DNA from laser-capture microdissected Hodgkin Reed-Sternberg cells. ${ }^{127}$ The same finding was uncovered using comparative genomic hybridization to test primary mediastinal large B-cell lymphoma, a neoplasm clinically and histomorphologically similar to classical Hodgkin Lymphoma. ${ }^{128}$

More recently, integrated copy number data from high-density single-nucleotide polymorphism arrays were paired with transcriptional profiles and identified highly significant amplification specifically of 9p24.1 in classical Hodgkin lymphoma cell lines with resultant overexpression of the $P D-L 1$ and $P D$ $L 2$ genes. ${ }^{16}$ Increased $P D-L 1$ gene expression was additionally identified in $38 \%$ of microdissected Hodgkin Reed-Sternberg cells from primary nodular sclerosis subtype classical Hodgkin lymphomas, and this finding correlated tightly with increased PD-L1 protein expression by immunohistochemistry. In primary mediastinal large B-cell lymphoma, amplification of 9p24.1 also has been associated with increased PD-L2 expression by immunohistochemistry. ${ }^{129}$ Interestingly, certain extranodal large B-cell lymphomas, including primary central nervous system lymphomas and primary testicular lymphomas, also harbor 9p24.1/ $P D-L 1 / P D-L 2$ copy number alterations. ${ }^{130}$

To further investigate the PD-L1 protein expression in primary tumors, large-scale immunohistochemistry analyses of a variety of hematologicaal neoplasms, including subtypes of classical Hodgkin lymphoma and related entities were pursued. ${ }^{131}$ Strong membranous PD-L1 labeling of Hodgkin Reed-Sternberg cells was identified in $84 \%$ of nodular sclerosis classical Hodgkin lymphoma, $88 \%$ of mixed cellularity classical Hodgkin lymphoma, and $100 \%$ of classical Hodgkin lymphomanot otherwise specified. Of these, $82 \%$ showed at least $90 \%$ of the Hodgkin Reed-Sternberg cells to be positive for PD-L1. Additionally, in the majority of these cases, at least $20 \%$ of the total tumor cellularity, including nonmalignant tissue macrophages, showed strong membranous PD-L1 expression. In a subsequent study, a fluorescence in situ hybridization-based assay was employed to investigate the correlation between 9p24.1 alterations and clinical outcomes using 108 classical Hodgkin lymphoma biopsies. ${ }^{132}$ In this cohort, $97 \%$ of cases showed concordant alterations of $P D-L 1$ and $P D-L 2$ loci, with copy gain and amplification identified in 56 and $36 \%$ of cases, respectively; PD-L1 protein expression by immunohistochemistry correlated with copy number alterations. Most importantly, patients whose tumors showed 9p24.1 amplification were more likely to have advanced-stage disease and were associated with worse progression-free survival following standard induction therapy.

These biomarker-based studies have set the stage for a number of clinical trials aimed at examining the potential utility of PD-1 blockade in classical Hodgkin lymphoma. In one of the earliest such attempts, nivolumab was tested in 23 patients with relapsed or refractory Hodgkin lymphoma that had already received standard multi-agent chemotherapy. ${ }^{133}$ In a subgroup of 10 patients with available pretreatment tissue biopsies, all tumors showed $P D-L 1$ and $P D-L 2$ copy number gains or amplifications by fluorescence in situ hybridization and membranous protein expression by immunohistochemistry on the Hodgkin Reed-Sternberg cells. An $87 \%$ overall response rate was seen in 23 patients, with $17 \%$ demonstrating a complete response, $70 \%$ a partial response, and 13\% with stable disease; progression-free survival was $86 \%$ at 24 weeks. More recently, a trial was conducted in which 31 patients who had failed polytherapy (including brentuximab vedotin, an anti-CD30 antibody) received pembrolizumab. ${ }^{134}$ In this cohort, $16 \%$ experienced a complete response and $48 \%$ had a partial response, producing an overall response rate of $65 \%$. The progression-free survival was $69 \%$ at 24 weeks and $46 \%$ at 52 weeks. In these cases, as well, both PD-L1 and PD-L2 expression were found to be elevated. Importantly, in a small series of patients with relapsed/refractory primary central nervous system lymphomas and primary testicular 
lymphoma, which are two tumor types with a high rate of 9p24.1 amplification, single-agent PD-1 blockade resulted in clinical responses in all patients. ${ }^{60}$

The efficacy of PD-1 blockade in classical Hodgkin lymphoma and select other lymphoma types appears to be a direct result of 9p24.1 copy number alterations, whereas the majority of non-Hodgkin lymphomas have shown reduced clinical response rates, perhaps as a result of lacking these same chromosomal aberrations. In a clinical trial involving 81 patients with a variety of non-Hodgkin lymphomas, objective response rates of $40,36,15$, and $40 \%$ were observed among patients with follicular lymphomas, diffuse large B-cell lymphoma, mycosis fungoides, and peripheral T-cell lymphoma, respectively. ${ }^{135}$ Such results indicate that further exploration into the mechanisms behind effective PD-1 blockage are needed, particularly in hematological malignancies unrelated to classical Hodgkin lymphoma.

\section{Head and neck squamous cell carcinoma}

Head and neck squamous cell carcinoma is most often associated with either human papillomavirus (HPV) infection or tobacco/alcohol exposure. The HPV-positive tumors tend to occur in the oropharynx, are more sensitive to radiation therapy, and tend to have a better prognosis than their HPVnegative counterparts. The HPV-negative tumors tend to be associated with field cancerization and a higher mutational density, which may be attributable to their association with carcinogens and resultant p53 mutations. ${ }^{136}$ The HPV-positive tumors were predicted to be responsive to immunotherapy, due to the presence of preexisting immunity against viral antigens as well as their typical location in the lymphoid-rich Waldeyer's ring. Somewhat surprisingly, clinical trials of anti-PD-1 therapy have shown comparable activity with overall response rates of approximately $10-20 \%$ and only slightly greater efficacy in HPV+ tumors. ${ }^{137,138}$ In 2016, the FDA approved nivolumab and pembrolizumab as secondline therapy for head and neck squamous cell carcinoma. Numerous phase III trials are ongoing, many of which are assessing the efficacy of combinatorial PD-1/PD-L1 blockade with either CTLA-4 inhibition or chemotherapy and/or radiation. ${ }^{139}$

As with other tumor types, there is a high demand for biomarkers to guide patient selection. Estimates of PD-L1 prevalence in head and neck squamous cell carcinoma range from 30 to $70 \%$, and patterns of both adaptive and constitutive PD-L1 expression in both HPV+ and HPV- tumors have been identified. 126,140,141 When PD-L1 expression in this tumor type was explored in clinical trials for antiPD-1 as a possible predictors of response and survival to anti-PD-1, the collective results have been somewhat ambiguous. ${ }^{138,142,143}$ Some of the seemingly contradictory observations may be reflective of constitutive vs adaptive PD-L1 expression patterns in this tumor type. Further evaluation of PDL1 as a biomarker response to monotherapy is ongoing in phase III trials (NCT02252042, NCT02358031), and the first results highlighting the potential additive value of assessing PD-L2 expression in addition to PD-L1 as a potential biomarker of response for head and neck squamous cell carcinoma were just published. ${ }^{144}$

It is worth highlighting potential reasons why HPV-negative tumors may also respond to immune checkpoint-blocking agents. Although HPV-positive tumors tend to be more inflamed, HPV-negative tumors also contain immune infiltrates. Further, the relative proportion of immune cell subsets and checkpoint molecule expression is similar between virus-positive and -negative tumors. ${ }^{145}$ Finally, mutational burden has also been associated with response to immune checkpoint blockade, and HPV-negative tumors have a higher mutational burden when compared with their virus-positive counterparts.

\section{Colorectal carcinoma}

Colorectal carcinoma is the third most common cancer type in men and women in the United States and represents a significant burden of disease. In a study of anti-PD-1 pembrolizumab in patients with colorectal carcinoma who failed conventional therapy, patients with microsatellite-unstable tumors (mismatch repair deficient) demonstrated a $40 \%$ objective response rate compared with $0 \%$ of patients with microsatellite-stable tumors (mismatch repair proficient). ${ }^{35}$ Microsatellite-unstable tumors contain many features that foreshadowed potential responses to this class of agents. First, they contain thousands of mutations, resulting in a high rate of neo-epitope formation. These neo-epitopes provide ample substrate for immune cell targeting. Second, microsatellite-unstable tumors are characterized by abundant tumor-infiltrating lymphocytes, the majority of which are antitumor, cytotoxic CD8+ T cells. Finally, half of microsatellite-unstable colorectal carcinomas show the expression of PD-L1 in the tumor microenvironment, either on carcinoma or immune cells. ${ }^{146}$

The high response rates of patients with microsatellite-unstable tumors is promising. In May 2017, the FDA granted accelerated approval for the anti-PD-1 pembrolizumab for all tumors with mismatch repair-deficient/microsatellite-unstable tumors, irrespective of the primary site of origin (Figure 3). Unfortunately, only 5-15\% of colorectal cancers in the United States have this genotype. A small subset of patients with microsatellite-stable (mismatch repair proficient) colorectal tumors showed some disease control in the pembrolizumab trial, ${ }^{35}$ and efforts are currently underway to 
characterize the immune microenvironment of these tumors. Integrative analyses of large cohorts of colorectal cancer showed that the Immunoscore is a stronger prognostic marker of prognosis than microsatellite instability. ${ }^{45}$ Studies are ongoing to determine whether it may also be a stronger predictor of response to various chemotherapeutic or immune-based therapies. ${ }^{147}$

\section{Breast carcinoma}

Breast carcinoma is the most common cause of cancer in women in the United States and is second only to lung carcinoma in cancer-related deaths in women ${ }^{148}$; thus the use of immunotherapy in breast carcinoma has the potential to impact a significant number of patients. Emerging evidence indicates the presence of a robust and active tumor immune microenvironment in a subset of breast carcinomas. ${ }^{149}$ Indeed, the presence of an active tumor microenvironment is demonstrated even in preinvasive ductal carcinoma in situ, ${ }^{150}$ suggesting the possibility of exploring immunotherapy as a preventative strategy.

The majority of breast carcinoma immune microenvironment studies have been carried out in invasive ductal carcinoma. ${ }^{10,151,152}$ Triple-negative breast carcinomas (TNBC) and those with amplification of the human epidermal growth factor receptor-2 (HER-2) oncogene appear to be more immunogenic than luminal type, or estrogen receptor (ER) positive, breast carcinomas, both on the basis of higher degree of tumor-infiltrating lymphocytes and increased immune gene signatures in the former tumor types. ${ }^{149}$ The potential to target the immune system in TNBC is particularly attractive, as these tumors not only tend to have a higher mutational burden (and thus increased potential neo-antigenicity) than other subsets of breast carcinoma but they also currently lack targeted treatment options.
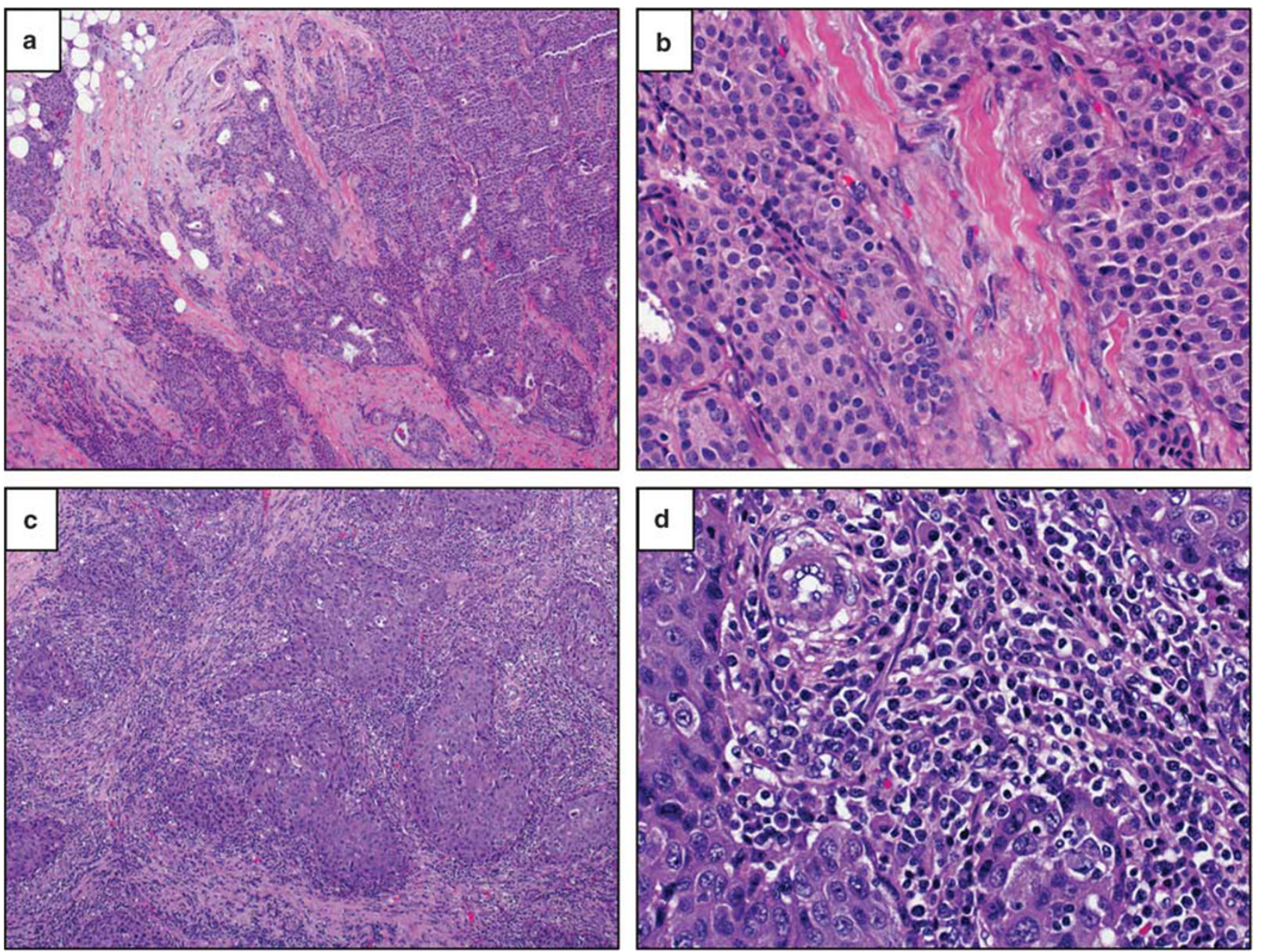

Figure 6 In breast carcinomas, tumor-infiltrating lymphocytes are scored as the percentage of stromal space within the tumor area occupied by mononuclear immune cells. The degree and composition of tumor-infiltrating lymphocytes varies across tumor subtypes and primary organ sites. (a, b) Here a primary luminal A-type breast carcinoma (ER+/PR+/HER-2-/Ki67-low) contains minimal tumorinfiltrating lymphocytes ( $<5 \%$ of stromal area) (H\&E, $\times 40$ and $\times 400$, original magnification). (c, d) In contrast, a primary HER-2+ breast carcinoma (ER - /PR - /HER-2+) contains brisk tumor-infiltrating lymphocytes (overall $80 \%$ of stromal area), qualifying as 'lymphocyte predominant breast cancer' (H\&E, $\times 40$ and $\times 400$, original magnification). 
The immune microenvironment in breast carcinoma has been largely defined by the presence and composition of tumor-infiltrating lymphocytes, which are most pronounced in TNBC and HER-2 ${ }^{+}$ carcinomas and are emerging as promising prognostic and predictive biomarkers. ${ }^{151,152}$ An international working group proposed recommendations for assessing tumor-infiltrating lymphocytes in breast carcinoma on hematoxylin and eosin sections, ${ }^{153}$ which will ideally lead to standardized scoring among studies. Tumor-infiltrating lymphocytes are assessed as a continuous variable of the percentage of the tumor stromal area occupied by lymphocytes (Figure 6), with a cutoff of 50-60\% stromal lymphocytes used to define 'lymphocyte-predominant breast carcinoma'.

Medullary carcinomas are a special subtype of breast carcinomas largely defined by the presence of a brisk lymphoplasmacytic infiltrate and have long been recognized to have a relatively favorable prognosis. ${ }^{154}$ The presence of high tumorinfiltrating lymphocytes is also associated with improved prognosis in TNBC and HER-2 ${ }^{+}$invasive ductal carcinomas. ${ }^{151,152}$ In addition, the presence of brisk tumor-infiltrating lymphocytes in the tumor bed after neoadjuvant therapy is associated with improved prognosis in TNBC. Finally, the presence of tumor-infiltrating lymphocytes in the pretreatment tumor is predictive of a favorable response to neoadjuvant chemotherapy in TNBC, as measured by the degree of pathological complete response. ${ }^{151}$ Studies are conflicting regarding whether there is an association between tumor-infiltrating lymphocytes and response to neoadjuvant anti-HER-2 targeted therapy. Among tumor-infiltrating lymphocyte subsets, the presence of $\mathrm{CD}^{+}$cytotoxic T cells is favorable, whereas the presence of $\mathrm{FoxP}^{+}$regulatory $\mathrm{T}$ cells is unfavorable, with evidence that a high CD8/FOXP3 ratio after neoadjuvant chemotherapy predicts overall survival. ${ }^{155}$

The role of immune checkpoint pathways is also under exploration in breast carcinoma. PD-L1 can be expressed by the carcinoma cells or immune cells, with increased expression seen in the TNBC and HER-2 ${ }^{+}$carcinomas. ${ }^{10,152}$ PD-L1 expression correlates with ER negativity and the overall degree of lymphocytes within the tumor in invasive ductal carcinomas, suggesting a component of adaptive immune expression of PD-L1. ${ }^{10,149}$ In contrast, in lobular carcinomas, PD-L1 expression is unrelated to the ER status of degree of tumor-infiltrating lymphocytes in the tumor, ${ }^{156}$ suggesting a component of constitutive or innate expression of PD-L1 by the carcinoma cells. Studies are conflicting regarding the association between PD-L1 expression and prognosis in breast carcinoma, likely reflecting the heterogeneity in PD-L1 assays and scoring between studies. ${ }^{157}$

Various immunotherapeutic strategies are under clinical investigation in breast carcinoma, including not only immune checkpoint inhibition but also peptide-based vaccines, immune cell transfer, and the administration of costimulatory antibodies. ${ }^{149,152,158}$ Indeed, trastuzumab, a monoclonal antibody targeting HER-2, is itself an immunotherapy with at least a component of its clinical efficacy due to stimulation of the immune response. ${ }^{158}$ Among checkpoint inhibitors, those targeting the PD-1/PD-L1 pathway have been most extensively studied, although agents targeting CTLA4 and LAG3 are also under investigation. ${ }^{149,152}$ Anti-PD-1/PD-L1 agents have shown promising results in patients with metastatic TNBC, with higher response rates in patients with PD-L1-positive tumors ${ }^{152}$; however, a subset of patients with PD-L1-negative tumors also demonstrates clinical response. Clinical trials of immune checkpoint inhibitors in the neoadjuvant setting, ${ }^{159}$ as well as coupling traditional therapeutic approaches such as chemotherapy with immune checkpoint inhibition, are also under investigation. ${ }^{152,158}$ As in other tumor types, the optimal biomarker for pathological prediction of response and trial inclusion remains unclear.

\section{Conclusions and future considerations}

The list of FDA-approved indications for immune checkpoint inhibitors as single agent or combinatory therapy is rapidly expanding, with anticipated approvals of new indications and new agents. With the expanding use of immunotherapy, there is a clear need for improved biomarker development. Biomarker development can be useful on not only on a perpatient basis but also in identifying tumor types most likely to respond to therapy. There are many solid tumor types such as thyroid or neuroendocrine tumors, which are not classically recognized as immune infiltrated. It is possible that if immune checkpoint blockade is to be effective tumor types such as these, it may be in the form of combination therapy, ie, an agent such as a tumor vaccine or even a small-molecule inhibitor could be used to incite a host response against tumor, followed by immune checkpoint blockade to protect and potentiate the resultant immune response. The preexisting paradigm for biomarker identification in the era of oncogenic targeted therapy, in which the presence of a given oncogene mutation is predictive of response, is not applicable to immunotherapeutic agents. There are numerous pathways dictating the interaction between a tumor and the immune cells, and distilling this interaction to a single marker is an oversimplification. Future biomarker strategies will undoubtedly include a more comprehensive assessment of both the innate and adaptive immune response to the tumor, as well as underlying features of the tumor itself.

The complexity of biomarker development for immune checkpoint blockade is exemplified by the development of PD-L1 immunohistochemistry as a diagnostic. Patients who are PD-L1-negative may demonstrate a clinical response to anti-PD-1/PD-L1 therapy, perhaps due to sampling error of a spatially 


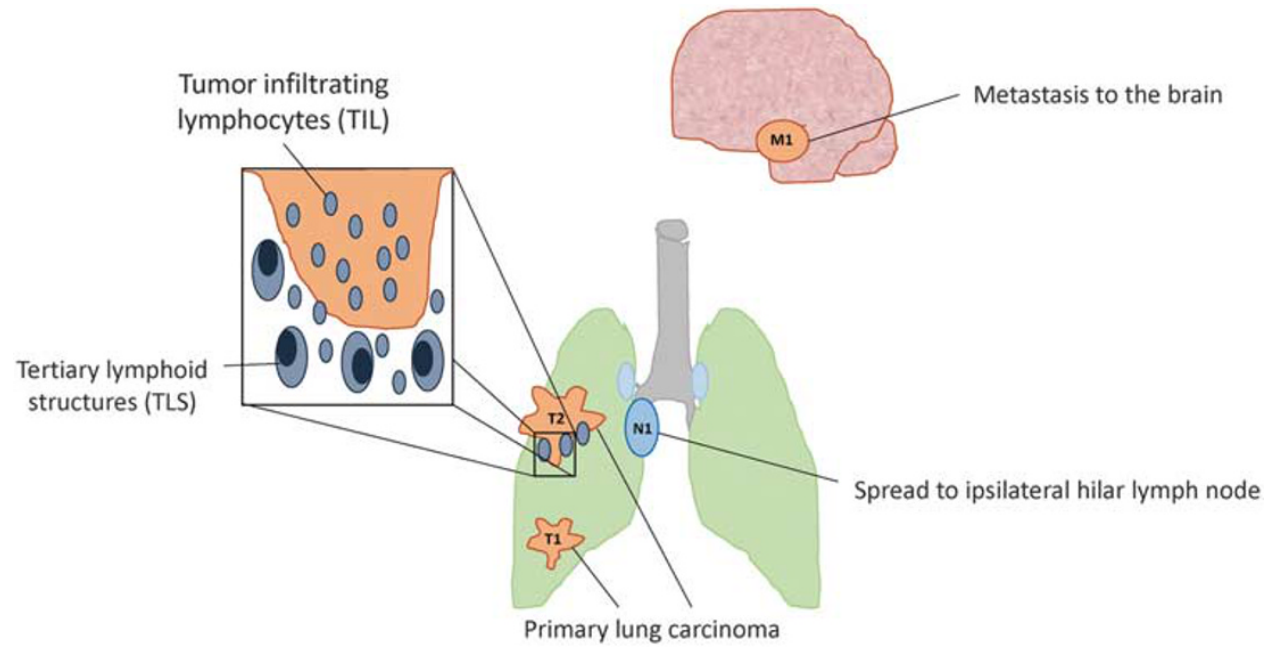

Figure 7 Future TNM staging systems for non-small cell lung carcinoma and other tumor types may include immune features. The current TNM staging system is based upon the degree of tumor invasion (T), presence and extent of nodal metastases (N), and presence of metastatic spread (M). Studies have shown that the presence and degree of tumor-infiltrating lymphocytes and tertiary lymphoid structures around the tumor bed may be favorable prognostic factors. Future incorporation of immune-based parameters as prognostic elements into the cancer staging system is likely in certain tumor types.

and temporally heterogeneous marker, issues with assay sensitivity, or simply the fact that PD-L1 may be an imperfect biomarker. Further underscoring the limitations of PD-L1 as a solitary marker, patients who are PD-L1-positive often do not respond to therapy. Additional enrichment for response in the PD-L1positive population may be possible by the assessment of whether PD-L1 is expressed in an adaptive rather than a constitutive manner, and those investigations are currently underway. Additional efforts are clearly needed to standardize the assays and scoring systems used, including clarification as to the cell type expressing PD-L1 to be scored. Data from preclinical models suggests that PD-L1 expression on tumor cells and immune cells can modulate T-cell function in the tumor microenvironment to a similar degree. ${ }^{160}$ Parallel studies in humans could help form the rational basis for a more unified PD-L1 immunohistochemistry scoring approach.

As the number of patients treated with checkpoint inhibition increases, the number of immune-related adverse events unique to this class of drugs will also increase. These include colitis, dermatitis, hepatitis, hypophysitis, myocarditis, pericarditis, and pneumonitis. Histopathological descriptions of many of these reactions have now been reported. ${ }^{161-165}$ The need for pathologists to maintain awareness of the histological manifestations of these drug-related events is critical for patient management, as is the importance of clear communication of clinical history by the treating physicians.

In conclusion, the recent success of immune-based cancer therapy is changing the practice of pathology. Surgical pathology specimens will be used for immune-based assays, including immunological and molecular biomarkers for therapeutic selection and monitoring. Elements of the tumor immune microenvironment are also recognized as independently prognostic in certain tumor types, contributing to the possibility of incorporation of immune parameters into the TNM-based staging system in the future (Figure 7). Surgical pathologists will have a critical role in assessing specimens, performing assays, and addressing questions from treating physicians, oncologists, and patients regarding predictive and prognostic immune biomarkers.

\section{Acknowledgments}

We thank Jessica Esandrio for administrative assistance. This work was supported by the Melanoma Research Alliance (to JMT); Bristol-Myers Squibb (JMT, RAA); Sidney Kimmel Cancer Center Core Grant P30 CA006973 (to JMT, RAA); the National Cancer Institute NIH Grant R01 CA142779 (to JMT); NIH Grant T32 CA193145 (to TRC); Center for Immuno-Oncology, Dana-Farber Cancer Institute (to SJR); The National Cancer Institute of France (INCa), the Canceropole Ile de France, INSERM, the Cancer research for personalized medicine (CARPEM), Paris Alliance of Cancer Research Institutes (PACRI), the LabEx Immuno-oncology, the Society for Immunotherapy of Cancer (SITC) (to JG). We were also supported by the Bloomberg-Kimmel Institute for Cancer Immunotherapy and a Stand Up To CancerCancer Research Institute Cancer Immunology Translational Cancer Research Grant (SU2C-AACRDT1012). Stand Up To Cancer is a program of the Entertainment Industry Foundation administered by the American Association for Cancer Research.

\section{Disclosure/conflict of interest}

RAA receives grant funding from Bristol-Meyers Squibb (BMS) and Stand Up 2 Cancer and is an 
advisory board member for BMS and Merck. AC-M receives grant funding from BMS. JG receives grant funding from Astra-Zeneca, MedImmune, Janssen; is co-founder and chairman of the advisory board of HalioDx; and is a consultant/advisory board member for BMS, Merck, Astra-Zeneca, GSK, AMGEN, IObiotech, Northwest Biotherapeutics, Actelion, Novartis, Incyte, Kite Pharma, Mologen, Compugen, NanoString, and Illumina. DLR receives grant funding from Astra Zeneca, Cepheid, Navigate/ Novartis, Gilead Sciences, Pierre Fabre, and Perkin Elmer; is a consultant or advisor to Astra Zeneca, Agendia, Bethyl Labs, Biocept, BMS, Cell Signaling Technology, Merck, OptraScan, Perkin Elmer, and Ultivue; and holds equity in Metamark Genetics and PixelGear. SJR receives grant funding from BMS and is a consultant/advisory board member for BMS and Perkin-Elmer. JMT receives grant funding from BMS and is a consultant/advisory board member for BMS, Merck, and Astra-Zeneca. LMS served as an advisory board member for Genentech and consults for Research to Practice. The other authors (ASB, TRC, NAG, SJP) declare no conflict of interest.

\section{References}

1 Gajewski TF, Schreiber H, Fu YX. Innate and adaptive immune cells in the tumor microenvironment. Nat Immunol 2013;14:1014-1022.

2 Vesely MD, Kershaw MH, Schreiber RD, et al. Natural innate and adaptive immunity to cancer. Annu Rev Immunol 2011;29:235-271.

3 Fridman WH, Pages F, Sautes-Fridman C, et al. The immune contexture in human tumours: impact on clinical outcome. Nat Rev Cancer 2012;12:298-306.

4 Galon J, Costes A, Sanchez-Cabo F, et al. Type, density, and location of immune cells within human colorectal tumors predict clinical outcome. Science 2006;313:1960-1964.

5 Angell H, Galon J. From the immune contexture to the Immunoscore: the role of prognostic and predictive immune markers in cancer. Curr Opin Immunol 2013;25:261-267.

6 Barber DL, Wherry EJ, Masopust D, et al. Restoring function in exhausted CD8 T cells during chronic viral infection. Nature 2006;439:682-687.

7 Taube JM, Anders RA, Young GD, et al. Colocalization of inflammatory response with B7-h1 expression in human melanocytic lesions supports an adaptive resistance mechanism of immune escape. Sci Transl Med 2012;4:127ra137.

8 Velcheti V, Schalper KA, Carvajal DE, et al. Programmed death ligand-1 expression in non-small cell lung cancer. Lab Invest 2014;94:107-116.

9 Lipson EJ, Vincent JG, Loyo M, et al. PD-L1 expression in the Merkel cell carcinoma microenvironment: association with inflammation, Merkel cell polyomavirus and overall survival. Cancer Immunol Res 2013;1:54-63.

10 Cimino-Mathews A, Thompson E, Taube JM, et al. PD-L1 (B7-H1) expression and the immune tumor microenvironment in primary and metastatic breast carcinomas. Hum Pathol 2016;47:52-63.
11 Schalper KA, elcheti V, Carvajal D, et al. In situ tumor PD-L1 mRNA expression is associated with increased TILs and better outcome in breast carcinomas. Clin Cancer Res 2014;20:2773-2782.

12 Yanik EL, Kaunitz GJ, Cottrell TR, et al. Association of HIV status with local immune response to anal squamous cell carcinoma: implications for immunotherapy. JAMA Oncol 2017;3:974-978.

13 Chen CL, Pan QZ, Zhao JJ, et al. PD-L1 expression as a predictive biomarker for cytokine-induced killer cell immunotherapy in patients with hepatocellular carcinoma. Oncoimmunology 2016;5: e1176653.

14 Xu C, Fillmore CM, Koyama S, et al. Loss of Lkb1 and Pten leads to lung squamous cell carcinoma with elevated PD-L1 expression. Cancer Cell 2014;25: 590-604.

15 Parsa AT, Waldron JS, Panner A, et al. Loss of tumor suppressor PTEN function increases B7-H1 expression and immunoresistance in glioma. Nat Med 2007;13:84-8.

16 Green MR, Monti S, Rodig SJ, et al. Integrative analysis reveals selective 9p24.1 amplification, increased PD-1 ligand expression, and further induction via JAK2 in nodular sclerosing Hodgkin lymphoma and primary mediastinal large B-cell lymphoma. Blood 2010;116:3268-3277.

17 Lastwika KJ, Wilson W 3rd, Li QK, et al. Control of PD-L1 expression by oncogenic activation of the AKTmTOR pathway in non-small cell lung cancer. Cancer Res 2016;76:227-238.

18 Van Allen EM, Golay HG, Liu Y, et al. Long-term benefit of PD-L1 blockade in lung cancer associated with JAK3 activation. Cancer Immunol Res 2015;3: 855-863.

19 Green MR, Rodig S, Juszczynski P, et al. Constitutive AP-1 activity and EBV infection induce PD-L1 in Hodgkin lymphomas and posttransplant lymphoproliferative disorders: implications for targeted therapy. Clin Cancer Res 2012;18:1611-1618.

20 Pardoll DM. The blockade of immune checkpoints in cancer immunotherapy. Nat Rev Cancer 2012;12: 252-264.

21 Topalian SL, Taube JM, Anders RA, et al. Mechanismdriven biomarkers to guide immune checkpoint blockade in cancer therapy. Nat Rev Cancer 2016;16: 275-287.

22 Littman DR. Releasing the brakes on cancer immunotherapy. Cell 2015;162:1186-1190.

23 Ribas A. Releasing the brakes on cancer immunotherapy. N Engl J Med. 2015;373:1490-1492.

24 Topalian SL, Sznol M, McDermott DF, et al. Survival, durable tumor remission, and long-term safety in patients with advanced melanoma receiving nivolumab. J Clin Oncol 2014;32:1020-1030.

25 Schadendorf D, Hodi FS, Robert C, et al. Pooled analysis of long-term survival data from phase II and phase III trials of ipilimumab in unresectable or metastatic melanoma. J Clin Oncol 2015;33: 1889-1894.

26 Chapman PB, Hauschild A, Robert C, et al. Improved survival with vemurafenib in melanoma with BRAF V600E mutation. N Engl J Med 2011;364: 2507-2516.

27 Sosman JA, Kim KB, Schuchter L, et al. Survival in BRAF V600-mutant advanced melanoma treated with vemurafenib. N Engl J Med 2012;366:707-714. 
28 Lipson EJ, Sharfman WH, Drake CG, et al. Durable cancer regression off-treatment and effective reinduction therapy with an anti-PD-1 antibody. Clin Cancer Res 2013;19:462-468.

29 Chiou VL, Burotto M. Pseudoprogression and immune-related response in solid tumors. J Clin Oncol 2015;33:3541-3543.

30 Hamid O, Robert C, Daud A, et al. Safety and tumor responses with lambrolizumab (anti-PD-1) in melanoma. N Engl J Med 2013;369:134-144.

31 Postow MA, Chesney J, Pavlick AC, et al. Nivolumab and ipilimumab versus ipilimumab in untreated melanoma. N Engl J Med 2015;372:2006-2017.

32 Hodi FS, Chesney J, Pavlick AC, et al. Combined nivolumab and ipilimumab versus ipilimumab alone in patients with advanced melanoma: 2-year overall survival outcomes in a multicentre, randomised, controlled, phase 2 trial. Lancet Oncol 2016;17: 1558-1568

33 Sunshine J, Taube JM. PD-1/PD-L1 inhibitors. Curr Opin Pharmacol 2015;23:32-38.

34 Tumeh PC, Harview CL, Yearley JH, et al. PD-1 blockade induces responses by inhibiting adaptive immune resistance. Nature 2014;515:568-571.

35 Le DT, Uram JN, Wang H, et al. PD-1 blockade in tumors with mismatch-repair deficiency. N Engl J Med 2015;372:2509-2520.

36 Rizvi NA, Hellmann MD, Snyder A, et al. Mutational landscape determines sensitivity to PD-1 blockade in non-small cell lung cancer. Science 2015;348: 124-128.

37 Snyder A, Makarov V, Merghoub T, et al. Genetic basis for clinical response to CTLA-4 blockade in melanoma. N Engl J Med 2014;371:2189-2199.

38 Hugo W, Zaretsky JM, Sun L, et al. Genomic and transcriptomic features of response to anti-PD-1 therapy in metastatic melanoma. Cell 2016;165: $35-44$.

39 Shin DS, Zaretsky JM, Escuin-Ordinas $\mathrm{H}$, et al. Primary resistance to PD-1 blockade mediated by JAK1/2 mutations. Cancer Discov 2017;7:188-201.

40 Zaretsky JM, Garcia-Diaz A, Shin DS, et al. Mutations associated with acquired resistance to PD-1 blockade in melanoma. N Engl J Med 2016;375:819-829.

41 Galon J, Mlecnik B, Bindea G, et al. Towards the introduction of the 'Immunoscore' in the classification of malignant tumours. J Pathol 2014;232:199-209.

42 Mlecnik B, Tosolini M, Kirilovsky A, et al. Histopathologic-based prognostic factors of colorectal cancers are associated with the state of the local immune reaction. J Clin Oncol 2011;29:610-618.

43 Pagès F, Kirilovsky A, Mlecnik B, et al. In situ cytotoxic and memory $\mathrm{T}$ cells predict outcome in patients with early-stage colorectal cancer. J Clin Oncol 2009;27:5944-51.

44 Galon J, Mlecnik B, Marliot F, et al. Validation of the Immunoscore (IM) as a prognostic marker in stage I/II/ III colon cancer: results of a worldwide consortiumbased analysis of 1,336 patients. J Clin Oncol 2016;34 (Suppl):abstr 3500.

45 Mlecnik B, Bindea G, Angell HK, et al. Integrative analyses of colorectal cancer show immunoscore is a stronger predictor of patient survival than microsatellite instability. Immunity 2016;44:698-711.

46 Berghoff AS, Fuchs E, Ricken G, et al. Density of tumor-infiltrating lymphocytes correlates with extent of brain edema and overall survival time in patients with brain metastases. Oncoimmunology 2016;5: e1057388.

47 Galon J, Franck P, Marincola FM, et al. Cancer classification using the Immunoscore: a worldwide task force. J Transl Med 2012;10:205.

48 Galon J, Pages F, Marincola FM, et al. The immune score as a new possible approach for the classification of cancer. J Transl Med 2012;10:1.

49 Hirsch FR, McElhinny A, Stanforth D, et al. PD-L1 immunohistochemistry assays for lung cancer: results from phase 1 of the blueprint PD-L1 IHC assay comparison project. J Thorac Oncol 2017;12: 208-222.

50 Ratcliffe MJ, Sharpe A, Midha A, et al. Agreement between programmed cell death ligand-1 diagnostic assays across multiple protein expression cut-offs in non-small cell lung cancer. Clin Cancer Res 2017;23: 3585-3591.

51 Rimm DL, Han G, Taube JM, et al. A prospective, multi-institutional, pathologist-based assessment of 4 immunohistochemistry assays for PD-L1 expression in non-small cell lung cancer. JAMA Oncol 2017;3: 1051-1058.

52 Scheel AH, Dietel M, Heukamp LC, et al. Harmonized PD-L1 immunohistochemistry for pulmonary squamous-cell and adenocarcinomas. Mod Pathol 2016;29:1165-1172.

53 Gaule P, Smithy JW, Toki M, et al. A quantitative comparison of antibodies to programmed cell death 1 ligand 1. JAMA Oncol 2017;3:256-259.

54 Sunshine JC, Nguyen P, Kaunitz G, et al. PD-L1 Expression in melanoma: a quantitative immunohistochemical antibody comparison. Clin Cancer Res 2017;23:4938-4944.

55 Socinski M, Creelan B, Horn L, et al. NSCLC, metastatic CheckMate 026: a phase 3 trial of nivolumab vs investigator's choice (IC) of platinum-based doublet chemotherapy (PT-DC) as first-line therapy for stage iv/recurrent programmed death ligand 1 (PDL1) - positive NSCLC. Ann Oncol 2016;27(suppl_6): LBA7_PR.

56 Reck M, Rodriguez-Abreu D, Robinson AG, et al. Pembrolizumab versus chemotherapy for PD-L1positive non-small-cell lung cancer. N Engl J Med 2016;375:1823-1833.

57 McLaughlin J, Han G, Schalper KA, et al. Quantitative assessment of the heterogeneity of PD-L1 expression in non-small-cell lung cancer. JAMA Oncol 2016;2:46-54.

58 Rehman JA, Han G, Carvajal-Hausdorf DE, et al. Quantitative and pathologist-read comparison of the heterogeneity of programmed death-ligand 1 (PD-L1) expression in non-small cell lung cancer. Mod Pathol 2017;30:340-349.

59 Younes A, Santoro A, Shipp M, et al. Nivolumab for classical Hodgkin's lymphoma after failure of both autologous stem-cell transplantation and brentuximab vedotin: a multicentre, multicohort, single-arm phase 2 trial. Lancet Oncol 2016;17:1283-1294.

60 Nayak L, Iwamoto FM, LaCasce A, et al. PD-1 blockade with nivolumab in relapsed/refractory primary central nervous system and testicular lymphoma. Blood 2017;129:3071-3073.

61 Howitt BE, Sun HH, Roemer MG, et al. Genetic basis for PD-L1 expression in squamous cell carcinomas of the cervix and vulva. JAMA Oncol 2016;2:518-522.

62 Jarvinen AK, Autio R, Kilpinen S, et al. Highresolution copy number and gene expression 
microarray analyses of head and neck squamous cell carcinoma cell lines of tongue and larynx. Genes Chromosomes Cancer 2008;47:500-509.

63 Piha-Paul SA, Bennouna J, Albright A, et al. T-cell inflamed phenotype gene expression signatures to predict clinical benefit from pembrolizumab across multiple tumor types. J Clin Oncol 2016;34 (suppl):1536-1536.

64 Nghiem PT, Bhatia S, Lipson EJ, et al. PD-1 blockade with pembrolizumab in advanced merkel-cell carcinoma. N Engl J Med 2016;374:2542-2552.

65 Schalper KA, Brown J, Carvajal-Hausdorf D, et al. Objective measurement and clinical significance of TILs in non-small cell lung cancer. J Natl Cancer Inst 2015;107:dju435.

66 Hodi FS, O'Day SJ, McDermott DF, et al. Improved survival with ipilimumab in patients with metastatic melanoma. N Engl J Med 2010;363:711-723.

67 Ribas A, Puzanov I, Dummer R, et al. Pembrolizumab versus investigator-choice chemotherapy for ipilimumab-refractory melanoma (KEYNOTE-002): a randomised, controlled, phase 2 trial. Lancet Oncol 2015;16:908-918.

68 Robert C, Schachter J, Long GV, et al. Pembrolizumab versus ipilimumab in advanced melanoma. N Engl J Med 2015;372:2521-2532.

69 Larkin J, Chiarion-Sileni V, Gonzalez R, et al. Combined Nivolumab and Ipilimumab or Monotherapy in Untreated Melanoma. N Engl J Med 2015;373:23-34.

70 Kaunitz G, Cottrell T, Lilo M, et al. Melanoma subtypes demonstrate distinct PD-L1 expression profiles. Lab Invest 2017;97:1063-1071.

71 Taube JM, Young GD, McMiller TL, et al. Differential expression of immune-regulatory genes associated with PD-L1 display in melanoma: implications for PD-1 pathway blockade. Clin Cancer Res 2015;21: 3969-3976.

72 Rodic N, Anders RA, Eshleman JR., et al. PD-L1 expression in melanocytic lesions does not correlate with the BRAF V600E mutation. Cancer Immunol Res 2015;3:110-115.

73 Danilova L, Wang H, Sunshine J, et al. Association of PD-1/PD-L axis expression with cytolytic activity, mutational load, and prognosis in melanoma and other solid tumors. Proc Natl Acad Sci USA 2016;113: E7769-E77.

74 Obeid JM, Erdag G, Smolkin ME, et al. PD-L1, PD-L2 and PD-1 expression in metastatic melanoma: correlation with tumor-infiltrating immune cells and clinical outcome. Oncoimmunology 2016;5:e1235107.

75 Daud AI, Wolchok JD, Robert C, et al. Programmed death-ligand 1 expression and response to the antiprogrammed death 1 antibody pembrolizumab in melanoma. J Clin Oncol 2016;34:4102-4109.

76 Johnson DB, Bordeaux J, Kim JY, et al. Quantitative spatial profiling of PD-1/PD-L1 interaction and HLA-DR/IDO-1 predicts improved outcomes to antiPD-1 in metastatic melanoma. J Clin Oncol 2017;35:9517-9517.

77 Roh W, Chen PL, Reuben A, et al. Integrated molecular analysis of tumor biopsies on sequential CTLA-4 and PD-1 blockade reveals markers of response and resistance. Sci Transl Med 2017;9: eaah3560.

78 Kaufman HL, Russell J, Hamid O, et al. Avelumab in patients with chemotherapy-refractory metastatic Merkel cell carcinoma: a multicentre, single-group, open-label, phase 2 trial. Lancet Oncol 2016;17: 1374-1385.

79 Giraldo N, Kaunitz G, Cottrell T, et al. The differential association of PD-1, PD-L1, and CD8+ cells with presence of Merkel cell polyomavirus and response to pembrolizumab in patients with Merkel cell carcinoma (MCC). Cancer Res 2017;77:662-662.

80 Lipson EJ, Lilo MT, Ogurtsova A, et al. Basal cell carcinoma: PD-L1/PD-1 checkpoint expression and tumor regression after PD-1 blockade. J Immunother Cancer 2017;5:23.

81 Falchook GS, Leidner R, Stankevich E, et al. Responses of metastatic basal cell and cutaneous squamous cell carcinomas to anti-PD1 monoclonal antibody REGN2810. J Immunother Cancer 2016;4:70.

82 Lipson EJ, Bagnasco SM, Moore J Jr., et al. Tumor regression and allograft rejection after administration of anti-PD-1. N Engl J Med 2016;374:896-898.

83 Torre LA, Siegel RL, Jemal A. Lung cancer statistics. Adv Exp Med Biol 2016;893:1-19.

84 Masters GA, Temin S, Azzoli CG, et al. Systemic therapy for stage IV non-small-cell lung cancer: American Society of Clinical Oncology Clinical Practice Guideline update. J Clin Oncol 2015;33:3488-3515.

85 Kris MG, Johnson BE, Berry LD, et al. Using multiplexed assays of oncogenic drivers in lung cancers to select targeted drugs. JAMA 2014;311:1998-2006.

86 Shaw AT, Ou SH, Bang YJ, et al. Crizotinib in ROS1rearranged non-small-cell lung cancer. N Engl J Med 2014;371:1963-1671.

87 Garon EB, Rizvi NA, Hui R, et al. Pembrolizumab for the treatment of non-small-cell lung cancer. N Engl J Med 2015;372:2018-2028.

88 Herbst RS, Soria JC, Kowanetz M, et al. Predictive correlates of response to the anti-PD-L1 antibody MPDL3280A in cancer patients. Nature 2014;515: $563-567$.

89 Carbone DP, Reck M, Paz-Ares L, et al. First-line nivolumab in stage IV or recurrent non-small-cell lung cancer. N Engl J Med 2017;376:2415-2426.

90 Johnson BE. Divide and conquer to treat lung cancer. N Engl J Med 2016;375:1892-1893.

91 Dong ZY, Zhong W, Zhang XC, et al. Potential predictive value of TP53 and KRAS mutation status for response to PD-1 blockade immunotherapy in lung adenocarcinoma. Clin Cancer Res 2017;23: 3012-3024.

92 Lizotte PH, Ivanova EV, Awad MM, et al. Multiparametric profiling of non-small-cell lung cancers reveals distinct immunophenotypes. JCI Insight 2016;1:e89014.

93 Skoulidis F, Byers LA, Diao L, et al. Co-occurring genomic alterations define major subsets of KRASmutant lung adenocarcinoma with distinct biology, immune profiles, and therapeutic vulnerabilities. Cancer Discov 2015;5:860-877.

94 Koyama S, Akbay EA, Li YY, et al. STK11/LKB1 deficiency promotes neutrophil recruitment and proinflammatory cytokine production to suppress T-cell activity in the lung tumor microenvironment. Cancer Res 2016;76:999-1008.

95 Kadara H, Choi M, Zhang J, et al. Whole-exome sequencing and immune profiling of early-stage lung adenocarcinoma with fully annotated clinical followup. Ann Oncol 2017;28:75-82.

96 Cabillic F, Bouet-Toussaint F, Toutirais O, et al. Interleukin-6 and vascular endothelial growth factor 
release by renal cell carcinoma cells impedes lymphocyte-dendritic cell cross-talk. Clin Exp Immunol 2006;146:518-523.

97 Figel AM, Brech D, Prinz PU, et al. Human renal cell carcinoma induces a dendritic cell subset that uses T-cell crosstalk for tumor-permissive milieu alterations. Am J Pathol 2011;179:436-451.

98 Giraldo NA, Becht E, Pages F, et al. Orchestration and prognostic significance of immune checkpoints in the microenvironment of primary and metastatic renal cell cancer. Clin Cancer Res 2015;21:3031-3040.

99 Remark R, Alifano M, Cremer I, et al. Characteristics and clinical impacts of the immune environments in colorectal and renal cell carcinoma lung metastases: influence of tumor origin. Clin Cancer Res 2013;19: 4079-4091.

100 Sautes-Fridman C, Lawand M, Giraldo NA, et al. Tertiary lymphoid structures in cancers: prognostic value, regulation, and manipulation for therapeutic intervention. Front Immunol 2016;7:407.

101 Nakano O, Sato M, Naito Y, et al. Proliferative activity of intratumoral CD8(+) T-lymphocytes as a prognostic factor in human renal cell carcinoma: clinicopathologic demonstration of antitumor immunity. Cancer Res 2001;61:5132-5136.

102 Thompson RH, Dong H, Lohse CM, et al. PD-1 is expressed by tumor-infiltrating immune cells and is associated with poor outcome for patients with renal cell carcinoma. Clin Cancer Res 2007;13:1757-1761.

103 Giraldo NA, Becht E, Vano Y, et al. Tumor-infiltrating and peripheral blood t-cell immunophenotypes predict early relapse in localized clear cell renal cell carcinoma. Clin Cancer Res 2017;23:4416-4428.

104 Kondo $\mathrm{T}$, Nakazawa $\mathrm{H}$, Ito $\mathrm{F}$, et al. Favorable prognosis of renal cell carcinoma with increased expression of chemokines associated with a Th1type immune response. Cancer Sci 2006;97:780-786.

105 Thompson RH, Gillett MD, Cheville JC, et al. Costimulatory B7-H1 in renal cell carcinoma patients: Indicator of tumor aggressiveness and potential therapeutic target. Proc Natl Acad Sci USA 2004;101: 17174-17179.

106 Shin SJ, Jeon YK, Kim PJ, et al. Clinicopathologic analysis of PD-L1 and PD-L2 expression in renal cell carcinoma: association with oncogenic proteins status. Ann Surg Oncol 2016;23:694-702.

107 Yang JC, Sherry RM, Steinberg SM, et al. Randomized study of high-dose and low-dose interleukin-2 in patients with metastatic renal cancer. J Clin Oncol 2003;21:3127-3132.

108 Rosenberg SA.. IL-2: the first effective immunotherapy for human cancer. J Immunol 2014;192:5451-5458.

109 Topalian SL, Hodi FS, Brahmer JR, et al. Safety, activity, and immune correlates of anti-PD-1 antibody in cancer. N Engl J Med 2012;366:2443-2454.

110 Brahmer JR, Tykodi SS, Chow LQ, et al. Safety and activity of anti-PD-L1 antibody in patients with advanced cancer. N Engl J Med 2012;366: 2455-2465.

111 Motzer RJ, Rini BI, McDermott DF, et al. Nivolumab for metastatic renal cell carcinoma: results of a randomized phase II trial. J Clin Oncol 2015;33: 1430-1437.

112 Motzer RJ, Escudier B, McDermott DF, et al. Nivolumab versus everolimus in advanced renal-cell carcinoma. N Engl J Med 2015;373:1803-1813.
113 McDermott DF, Sosman JA, Sznol M, et al. Atezolizumab, an anti-programmed death-ligand 1 antibody, in metastatic renal cell carcinoma: long-term safety, clinical activity, and immune correlates from a phase Ia study. J Clin Oncol 2016;34:833-842.

114 Faraj SF, Munari E, Guner G, et al. Assessment of tumoral PD-L1 expression and intratumoral CD8+ $\mathrm{T}$ cells in urothelial carcinoma. Urology 2015;85: 703 e1-6.

115 Winerdal ME, Marits P, Winerdal M, et al. FOXP3 and survival in urinary bladder cancer. BJU Int 2011;108: 1672-1678.

116 Baras AS, Drake C, Liu JJ, et al. The ratio of CD8 to Treg tumor-infiltrating lymphocytes is associated with response to cisplatin-based neoadjuvant chemotherapy in patients with muscle invasive urothelial carcinoma of the bladder. Oncoimmunology 2016;5: e1134412.

117 Boorjian SA, Sheinin Y, Crispen PL, et al. T-cell coregulatory molecule expression in urothelial cell carcinoma: clinicopathologic correlations and association with survival. Clin Cancer Res 2008;14: 4800-4808.

118 Xylinas E, Robinson BD, Kluth LA, et al. Association of T-cell co-regulatory protein expression with clinical outcomes following radical cystectomy for urothelial carcinoma of the bladder. Eur J Surg Oncol 2014;40:121-127.

119 Nakanishi J, Wada Y, Matsumoto K, et al. Overexpression of B7-H1 (PD-L1) significantly associates with tumor grade and postoperative prognosis in human urothelial cancers. Cancer Immunol Immunother 2007;56:1173-1182.

120 Inman BA, Sebo TJ, Frigola X, et al. PD-L1 (B7-H1) expression by urothelial carcinoma of the bladder and BCG-induced granulomata: associations with localized stage progression. Cancer 2007;109:1499-1505.

121 Wang Y, Zhuang Q, Zhou S, et al. Costimulatory molecule B7-H1 on the immune escape of bladder cancer and its clinical significance. J Huazhong Univ Sci Technol Med Sci 2009;29:77-79.

122 Patel SP, Kurzrock R. PD-L1 expression as a predictive biomarker in cancer immunotherapy. Mol Cancer Ther 2015;14:847-856.

123 Herr HW, Schwalb DM, Zhang ZF, et al. Intravesical bacillus Calmette-Guerin therapy prevents tumor progression and death from superficial bladder cancer: ten-year follow-up of a prospective randomized trial. J Clin Oncol 1995;13:1404-1408.

124 Powles T, Eder JP, Fine GD, et al. MPDL3280A (antiPD-L1) treatment leads to clinical activity in metastatic bladder cancer. Nature 2014;515:558-562.

125 Rosenberg JE, Hoffman-Censits J, Powles T, et al. Atezolizumab in patients with locally advanced and metastatic urothelial carcinoma who have progressed following treatment with platinum-based chemotherapy: a single-arm, multicentre, phase 2 trial. Lancet 2016;387:1909-1920.

126 Malm IJ, Bruno TC, Fu J, et al. Expression profile and in vitro blockade of programmed death-1 in human papillomavirus-negative head and neck squamous cell carcinoma. Head Neck 2015;37:1088-1095.

127 Steidl C, Telenius A, Shah SP, et al. Genome-wide copy number analysis of Hodgkin Reed-Sternberg cells identifies recurrent imbalances with correlations to treatment outcome. Blood 2010;116:418-427. 
128 Bentz M, Barth TF, Bruderlein S, et al. Gain of chromosome arm $9 p$ is characteristic of primary mediastinal B-cell lymphoma (MBL): comprehensive molecular cytogenetic analysis and presentation of a novel MBL cell line. Genes Chromosomes Cancer 2001;30:393-401.

129 Shi M, Roemer MG, Chapuy B, et al. Expression of programmed cell death 1 ligand 2 (PD-L2) is a distinguishing feature of primary mediastinal (thymic) large B-cell lymphoma and associated with PDCD1LG2 copy gain. Am J Surg Pathol 2014;38: 1715-1723.

130 Chapuy B, Roemer MG, Stewart C, et al. Targetable genetic features of primary testicular and primary central nervous system lymphomas. Blood 2016;127: 869-881.

131 Chen BJ, Chapuy B, Ouyang J, et al. PD-L1 expression is characteristic of a subset of aggressive B-cell lymphomas and virus-associated malignancies. Clin Cancer Res 2013;19:3462-3473.

132 Roemer MG, Advani RH, Ligon AH, et al. PD-L1 and PD-L2 genetic alterations define classical hodgkin lymphoma and predict outcome. J Clin Oncol 2016;34:2690-2697.

133 Ansell SM, Lesokhin AM, Borrello I, et al. PD-1 blockade with nivolumab in relapsed or refractory Hodgkin's lymphoma. N Engl J Med 2015;372: 311-319.

134 Armand P, Shipp MA, Ribrag V, et al. Programmed death-1 blockade with pembrolizumab in patients with classical Hodgkin lymphoma after brentuximab vedotin failure. J Clin Oncol 2016;34: 3733-3739.

135 Lesokhin AM, Ansell SM, Armand P, et al. Nivolumab in patients with relapsed or refractory hematologic malignancy: preliminary results of a phase Ib study. J Clin Oncol 2016;34:2698-2704.

136 Westra WH, Taube JM, Poeta ML, et al. Inverse relationship between human papillomavirus-16 infection and disruptive p53 gene mutations in squamous cell carcinoma of the head and neck. Clin Cancer Res 2008;14:366-369.

137 Kim HS, Lee JY, Lim SH, et al. Association between PD-L1 and HPV status and the prognostic value of PDL1 in oropharyngeal squamous cell carcinoma. Cancer Res Treat 2016;48:527-536.

138 Bauml J, Seiwert TY, Pfister DG, et al. Pembrolizumab for platinum- and cetuximab-refractory head and neck cancer: results from a single-arm, phase II study. J Clin Oncol 2017;35:1542-1549.

139 Xie X, O'Neill W, Pan Q. Immunotherapy for head and neck cancer: the future of treatment? Expert Opin Biol Ther 2017;17:1-8.

140 Lyford-Pike S, Peng S, Young GD, et al. Evidence for a role of the PD-1:PD-L1 pathway in immune resistance of HPV-associated head and neck squamous cell carcinoma. Cancer Res 2013;73:1733-1741.

141 Feldman R, Gatalica Z, Knezetic J, et al. Molecular profiling of head and neck squamous cell carcinoma. Head Neck 2016;38(Suppl 1):E1625-38.

142 Chow LQ, Haddad R, Gupta S, et al. Antitumor activity of pembrolizumab in biomarker-unselected patients with recurrent and/or metastatic head and neck squamous cell carcinoma: results from the phase Ib KEYNOTE-012 expansion cohort. J Clin Oncol 2016;34:3838-3845.
143 Ferris RL, Blumenschein G Jr., Fayette J, et al. Nivolumab for recurrent squamous-cell carcinoma of the head and neck. N Engl J Med 2016;375:1856-1867.

144 Yearley JH, Gibson C, Yu N, et al. PD-L2 expression in human tumors: relevance to anti-PD-1 therapy in cancer. Clin Can Res 2017;23:3158-3167.

145 Lechner A, Schlosser H, Rothschild SI, et al. Characterization of tumor-associated T-lymphocyte subsets and immune checkpoint molecules in head and neck squamous cell carcinoma. Oncotarget 2017;8: 44418-44433.

146 Llosa NJ, Cruise M, Tam A, et al. The vigorous immune microenvironment of microsatellite instable colon cancer is balanced by multiple counterinhibitory checkpoints. Cancer Discov 2015;5:43-51.

147 Galon J, Angell HK, Bedognetti D, et al. The continuum of cancer immunosurveillance: prognostic, predictive, and mechanistic signatures. Immunity 2013;39:11-26.

148 Siegel RL, Miller KD, Jemal A. Cancer statistics, 2017. CA Cancer J Clin 2017;67:7-30.

149 Cimino-Mathews A, Foote JB, Emens LA. Immune targeting in breast cancer. Oncology (Williston Park) 2015;29:375-385.

150 Thompson E, Taube JM, Elwood H, et al. The immune microenvironment of breast ductal carcinoma in situ. Mod Pathol 2016;29:249-258.

151 Savas P, Salgado R, Denkert C, et al. Clinical relevance of host immunity in breast cancer: from TILs to the clinic. Nat Rev Clin Oncol 2016;13:228-241.

152 Burugu S, Asleh-Aburaya K, Nielsen TO. Immune infiltrates in the breast cancer microenvironment: detection, characterization and clinical implication. Breast Cancer 2017;24:3-15.

153 Salgado R, Denkert C, Demaria S, et al. The evaluation of tumor-infiltrating lymphocytes (TILs) in breast cancer: recommendations by an International TILs Working Group 2014. Ann Oncol 2015;26:259-271.

154 Moore OS Jr., Foote FW Jr. The relatively favorable prognosis of medullary carcinoma of the breast. Cancer 1949;2:635-642.

155 Ladoire S, Mignot G, Dabakuyo S, et al. In situ immune response after neoadjuvant chemotherapy for breast cancer predicts survival. J Pathol 2011;224: 389-400.

156 Thompson E, Taube JM, Kendrick-Asch RJ, et al. PDL1 expression and the immune microenvironment in primary invasive lobular carcinomas of the breast. Mod Pathol 2017;30:1551-1560.

$157 \mathrm{Li} \mathrm{X}, \mathrm{Li} \mathrm{M}$, Lian Z, et al. Prognostic role of programmed death ligand-1 expression in breast cancer: a systematic review and meta-analysis. Target Oncol 2016;11:753-761.

158 Kroemer G, Galluzzi L, Kepp O, et al. Immunogenic cell death in cancer therapy. Annu Rev Immunol 2013;31:51-72.

159 Nanda R, Liu Minetta C, Yau C, et al. Pembrolizumab plus standard neoadjuvant therapy for high-risk breast cancer (BC): results from I-SPY 2. J Clin Oncol 2017;35:506.

160 Lau J, Cheung J, Navarro A, et al. Tumour and host cell PD-L1 is required to mediate suppression of antitumour immunity in mice. Nat Commun 2017;8: 14572.

161 Naidoo J, Wang X, Woo KM, et al. Pneumonitis in patients treated with anti-programmed death-1/ 
programmed death ligand 1 therapy. J Clin Oncol 2017;35:709-717.

162 Johnson DB, Balko JM, Compton ML, et al. Fulminant myocarditis with combination immune checkpoint blockade. N Engl J Med 2016;375:1749-1755.

163 Curry JL, Tetzlaff MT, Nagarajan P, et al. Diverse types of dermatologic toxicities from immune checkpoint blockade therapy. J Cutan Pathol 2017;44: 158-176.
164 Chen JH, Pezhouh MK, Lauwers GY, et al. Histopathologic features of colitis due to immunotherapy with anti-PD-1 antibodies. Am J Surg Pathol 2017;41: 643-654.

165 Kaunitz G, Loss M, Rizvi H, et al. Cutaneous eruptions in patients receiving immune checkpoint blockade: clinicopathologic analysis of the non-lichenoid histologic pattern. Am J Surg Pathol 2017;41:13811389. 